\title{
FORMULAS, TABLES, AND CURVES FOR COMPUTING THE MUTUAL INDUCTANCE OF TWO COAXIAL CIRCLES
}

\author{
By Harvey L. Curtis and C. Matilda Sparks
}

ABSTRACT

The formulas for the mutual inductance of coaxial circles can be expressed either in terms of the radii of the circles and the distance between them, or in terms of a parameter which is a function of these dimensions. Both types of formulas are developed in this paper, and tables prepared to aid in the computation by each type. Charts are included from which an approximate value of the mutual inductance can be read directly. A number of examples are given to show the methods of computation by the different formulas, tables, and charts.

\section{CONTENTS}

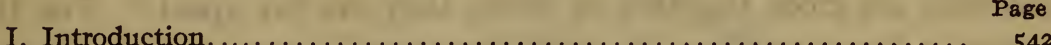

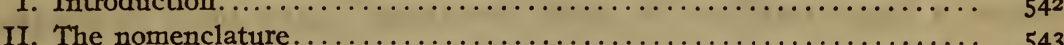

III. Derivation of series formulas in terms of $k^{2}$ and $k^{\prime 2} \ldots \ldots \ldots \ldots \ldots \ldots .545$

IV. Formulas involving only the radii of the coils and the distance between

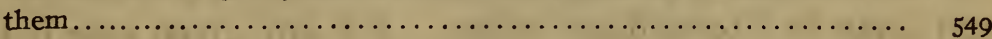

V. Use of tables to compute an inductance.................. $55^{2}$

VI. Determination of coaxial circles to have a desired mutual inductance... 553

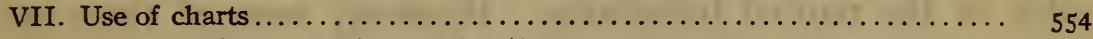

VIII. Mutual inductance of coaxial coils.................... 556

IX. Examples of use of charts, tables, and formulas. . . . . . . . . . 557

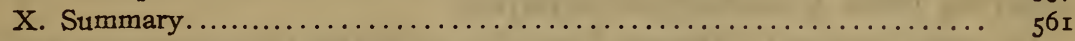

Appendix - Tables and charts for determining the mutual inductance of coaxial

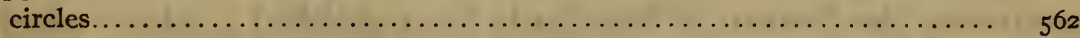

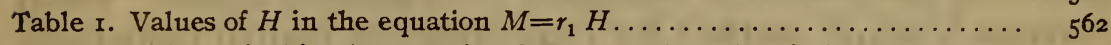

Table 2. Values of $H$ in the equation $M=r_{1} H$ when the circles are close to-

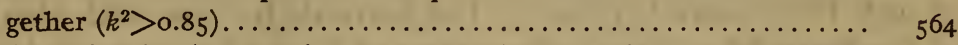

Table 3. Values of $H$ in the equation $M=r_{1} H$ when the circles are far apart

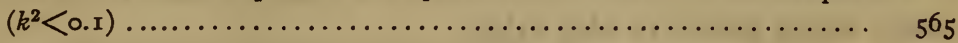

Table 4. Values of $k^{2}$ when $D$ is less than $A$-circles close together...... 566

Table 5. Values of $k^{2}$ when $D$ is greater than $A$-circles far apart........ 568

Table 6. Values of $P$ in the equation $M=\frac{a^{2}}{A} P$ when $D$ is less than $A$-circles near together........................... ${ }_{569}^{69}$

Table 7. Values of $P$ in the equation $M=\frac{a^{2}}{A} P$ when $D$ is greater than $A$ and

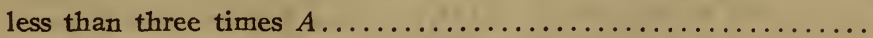


Table 8. Values of $S$ in the equation $M=\frac{a^{2} A^{2}}{D^{3}} S$ when $D$ is greater than $3 A-$ Page. circles far apart................................ 574

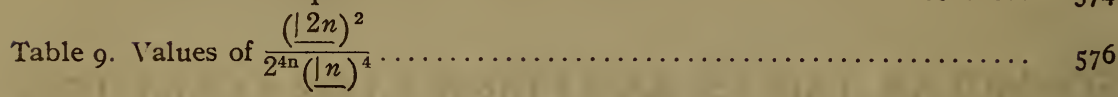

Fig. r. Diagrammatic cross section of two coaxial circles showing dimensions. . 544

Fig. 2. Chart showing relative size of circles and distance between them to give a definite value of $\frac{M}{A}$. General survey of a large region ..... Facing

Fig. 3. Chart showing relative size of circles and distance between them to give a definite value of $\frac{M}{A}$. Important region in detail......... Facing

Fig. 4. Chart showing the relation of $\frac{M}{A}$ to $\frac{D}{A}$ for different values of $\frac{a}{A}$.... Facing

\section{INTRODUCTION}

An exact formula for the mutual inductance of coaxial circles was derived by Maxwell ${ }^{1}$ in terms of elliptic integrals. However, it does not readily lend itself to computation either when the coils are close together or when they are far apart. ${ }^{2}$ For this reason a large number of series formulas ${ }^{3}$ have been developed. Some of these give accurate values of the mutual inductance when the two coils are close together, others when the coils are far apart, and some in intermediate ranges. For any given case it is possible to select one or more formulas which will give an accurate value of the mutual inductance. However, most of these are somewhat complicated, and difficulty is often experienced in applying them to numerical examples.

By using several different formulas to make the necessary computations, the Bureau of Standards has published a table ${ }^{4}$ which provides a simple method for computing the mutual inductance of any two coaxial circles. The formula for use with this table is of the form $M=\sqrt{A a} C$, the values of $C$ as a function of $k^{\prime}$ (defined later) being given in the table.

\footnotetext{
1 Electricity and Magnetism, 2, art. 7or.

${ }^{2}$ Computation by this formula has been simplified, and its range of usefulness greatly extended by the tables of elliptic integrals recently published by Nagaoka and Sakurai. These tables, entitled "Tables of Theta Functions, Elliptic Integrals $K$ and $E$, and Associated Coefficients in the Numerical Calculation of Elliptic Functions," were published by the Tokyo Institute of Physical and Chemical Research in December, 1922.

3 These formulas have been collected and their limitations pointed out by Rosa and Grover. B. S. Bull., 8, pp. 6-32, B. S. Sci. Paper No. 169; and 14, pp. 538-544, B. S. Sci. Paper No. 320.

"This is published in B. S. Circular No. 74 , entitled "Radio Instruments and Measurements," p. 275. The table was prepared by Dr. F. W. Grover, one of the authors of the circular. However, the method of computing the table is not indicated.
} 
In the present paper formulas are derived and tables of constants given for computing by two methods the mutual inductance of any two coaxial circles. The tables can also be used in solving the inverse problem, viz, determining the dimensions of circles which will give a desired mutual inductance. In addition, charts are given from which an approximate value of the mutual inductance can be read directly, and from which the dimensions of circles to give a desired mutual inductance can be determined by inspection.

\section{THE NOMENCLATURE}

The constants which are generally measured, and from which the others are derived, are $A$, the radius of the larger circle; $a$, the radius of the smaller circle; and $D$, the distance between the centers of the circles. From these are determined the constants used in computation, viz:

$$
\begin{gathered}
r_{1}{ }_{1}=(A+a)^{2}+D^{2} \\
r_{2}{ }_{2}=(A-a)^{2}+D^{2} \\
k^{2}=\frac{r_{1}{ }_{1}-r_{2}{ }_{2}}{r_{1}{ }_{1}}=\frac{4 A a}{(A+a)^{2}+D^{2}}=\frac{\frac{4 \mathrm{a}}{A}}{\left(\mathrm{I}+\frac{a}{A}\right)^{2}+\frac{D^{2}}{A^{2}}} \\
k^{\prime 2}=\mathrm{I}-k^{2}=\frac{r_{2}^{2}}{r_{1}^{2}}=\frac{(A-a)^{2}+D^{2}}{(A+a)^{2}+D^{2}}=\frac{\left(\mathrm{I}-\frac{a}{A}\right)^{2}+\frac{D^{2}}{A^{2}}}{\left(\mathrm{I}+\frac{a}{A}\right)^{2}+\frac{D^{2}}{A^{2}}} \\
k_{1}=\frac{4 a A}{\left(r_{1}+r_{2}\right)^{2}}=\frac{4 a A}{\left[\sqrt{(A+a)^{2}+D^{2}}+\sqrt{\left.(A-a)^{2}+D^{2}\right]^{2}}\right.}
\end{gathered}
$$




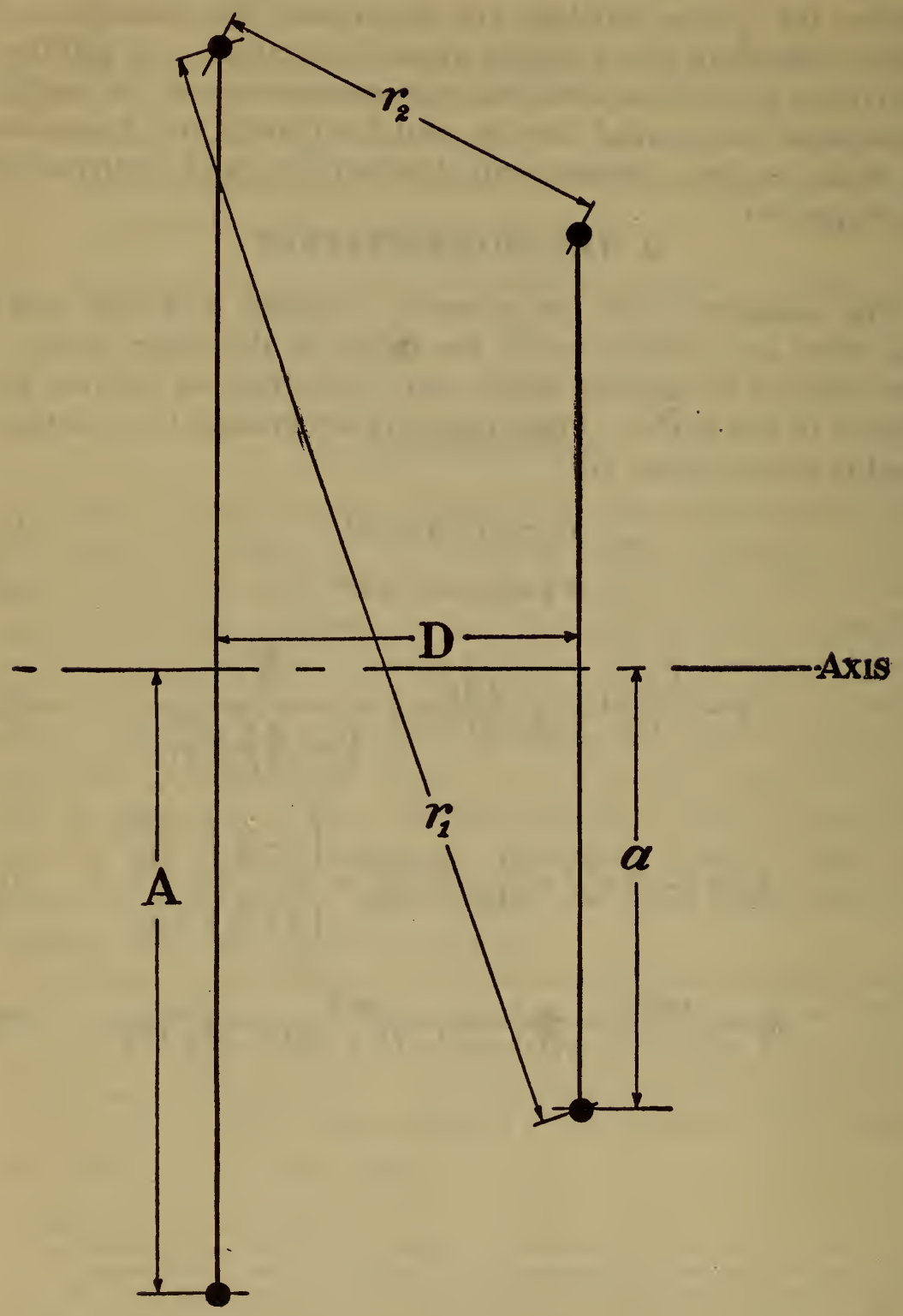

FIG. I.-Diagrammatic cross section of two coaxial circles showing dimensions 
When $D=0$

$$
k_{1}=\frac{a}{A}
$$

When $D \neq 0$

$$
k_{1}=\frac{\frac{4 \mathrm{a}}{A}}{\left[\sqrt{\left(\mathrm{I}+\frac{a}{A}\right)^{2}+\frac{D^{2}}{A^{2}}}+\sqrt{\left(\mathrm{1}-\frac{a}{A}\right)^{2}+\frac{D^{2}}{A^{2}}}\right]^{2}}
$$

When $D$ is large relative to $A$

$$
k_{1}=\frac{\frac{4 a}{A} \cdot \frac{A^{2}}{D^{2}}}{\left[\sqrt{\mathrm{I}+\frac{A^{2}}{D^{2}}\left(\mathrm{I}+\frac{a}{A}\right)^{2}}+\sqrt{\left.\mathrm{I}+\frac{A^{2}}{D^{2}}\left(\mathrm{I}-\frac{a}{A}\right)^{2}\right]^{2}}\right.}
$$

The above is the nomenclature used by Rosa and Grover in Scientific Paper No. 169, with the exception that $D$ is used for $d$. The geometric meaning of $r_{1}$ and $r_{2}$ is shown in Figure $I$.

Since $k^{\prime}=\frac{r_{2}}{r_{1}}$, and since $r_{2}$ is always less than $r_{1}$, then $k^{\prime}$ is always less than unity, which value it approaches as a limiting case. Likewise, all values of $k$ lie between zero and unity.

The other terms used are the complete elliptic integrals ${ }^{5} K$ and $E$. They will be defined where used in terms of series.

The natural logarithm will be indicated by the symbol "logn" while the symbol "log" will be used for common logarithms only.

\section{DERIVATION OF SERIES FORMULAS IN TERMS OF $k^{2}$ AND $k^{\prime 2}$}

There are well-known series for expanding the elliptic integrals However, the application of these series to the elliptic integral formula for mutual inductance is of ten a tedious process. A simple transformation will simplify the application.

The elliptic integral formula as given by Maxwell is

$$
M=4 \pi \sqrt{A a}\left[\left(\frac{2}{k}-k\right) K-\frac{2}{k} E\right]
$$

5 The complete elliptic integral of the first kind is represented by $K$ instead of $F$, which was used in B. S. Sci. Paper No. 169 . 
From equation (3) $2 \sqrt{A a}=k r_{1}$. Putting this value in equation (8)

$$
M=2 \pi r_{1}\left[\left(2-k^{2}\right) K-2 E\right]
$$

If the expansion is to be in terms of $k^{\prime 2}$ (equal to $\mathrm{I}-k^{2}$ ) then

$$
M=2 \pi r_{1}\left[\left(\mathrm{I}+k^{\prime 2}\right) K-2 E\right]
$$

The series values of $K$ and $E$ in terms of $k$ are ${ }^{\circ}$

$$
\begin{gathered}
K=\frac{\pi}{2} \sum_{n=0}^{\infty} \frac{(\underline{\mid 2 n})^{2}}{2^{4 \mathrm{n}}(\mid \underline{n})^{4}} k^{2 \mathrm{n}} \\
E=-\frac{\pi}{2} \sum_{n=0}^{\infty} \frac{(\mid 2 n)^{2}}{2^{4 \mathrm{n}}(\underline{\mid n})^{4}} \cdot \frac{\mathrm{I}}{2 n-\mathrm{I}} k^{2 \mathrm{n}}
\end{gathered}
$$

Substituting these values in (9)

$$
M=\frac{\pi^{2} r_{1} k^{4}}{8} \sum_{n=0}^{\infty} \frac{(\mid 2 n)^{2}}{2^{4 n}(\mid \underline{n})^{4}} \cdot \frac{2(2 n+\mathrm{I})^{2}}{(n+\mathrm{I})(n+2)} k^{2 n}
$$

This ${ }^{7}$ may be written as $M=r_{1} H$ where $H$ is a function of $k^{2}$. When the coils are far apart, or when one coil is much larger than the other, $k^{2}$ is small and the series is rapidly convergent. In this region $H$ is very nearly proportional to $k^{4}$.

The expressions for $K$ and $E$ in terms of $k^{\prime}$, given as equation (3) of Scientific Paper No. I69, can be written in the form

$$
\begin{aligned}
& K=\left(\log n \frac{4}{k^{\prime}}\right)\left[\mathrm{I}+\frac{\mathrm{I}^{2}}{2^{2}} k^{\prime 2}+\frac{\mathrm{I}^{2}}{2^{2}} \cdot \frac{3^{2}}{4^{2}} k^{\prime 4}+\cdots\right. \\
& \left.+\frac{\mathrm{I}^{2}}{2^{2}} \cdot \frac{3^{2}}{4^{2}} \cdots \cdot \frac{(2 n-\mathrm{I})^{2}}{(2 n)^{2}} k^{\prime 2 n}+\cdots\right] \\
& -\left[\frac{\mathrm{I}^{2}}{2^{2}} \frac{2}{\mathrm{I} \times 2} k^{\prime 2}+\frac{\mathrm{I}^{2}}{2^{2}} \cdot \frac{3^{2}}{4^{2}}\left(\frac{2}{\mathrm{I} \times 2}+\frac{2}{3 \times 4}\right) k^{\prime 4}+\cdots\right. \\
& \left.+\frac{\mathrm{I}^{2}}{2^{2}} \cdots \frac{(2 n-\mathrm{I})^{2}}{(2 n)^{2}}\left(\frac{2}{\mathrm{I} \times 2}+\frac{2}{3 \times 4}+\cdots+\frac{2}{(2 n-\mathrm{I}) 2 n}\right) k^{\prime 2 n}+\cdots\right] \\
& =\sum_{n=0}^{\infty} \frac{(\mid 2 n)^{2} k^{\prime 2 \mathrm{n}}}{2^{4 \mathrm{n}}(\underline{n})^{4}}\left[\frac{\mathrm{I}}{2} \log n \frac{\mathrm{I} 6}{k^{\prime 2}}-\frac{(2 n+\mathrm{I})^{2} k^{\prime 2}}{4(n+\mathrm{I})^{2}} \sum_{s=0}^{n} \frac{\mathrm{I}}{(s+\mathrm{I})(2 s+\mathrm{I})}\right]
\end{aligned}
$$

${ }^{6}$ B. S. Sci. Paper No. 169, p. 9.

7 This equation $\left(r_{3}\right)$ is the same as equation (5) of B. S. Sci. Paper No. 169. 


$$
\begin{aligned}
& E=\left(\operatorname{logn} \frac{4}{k^{\prime}}\right)\left[\frac{1}{2} k^{\prime 2}+\frac{\mathrm{I}^{2}}{2^{2}} \cdot \frac{3}{4} k^{\prime 4}+\cdots\right. \\
& +\frac{\mathrm{I}^{2}}{2^{2}} \cdot \frac{3^{2}}{4^{2}} \cdots \frac{(2 n-3)^{2}}{(2 n-2)^{2}} \cdot \frac{2 n-\mathrm{r}}{2 n} k^{\prime 2 n}+\cdots \\
& +\mathrm{I}-\frac{\mathrm{I}}{2}\left(\frac{\mathrm{I}}{\mathrm{I} \times 2}\right) k^{\prime 2}-\frac{\mathrm{I}^{2}}{2^{2}} \cdot \frac{3}{4}\left(\frac{2}{\mathrm{I} \times 2}+\frac{\mathrm{I}}{3 \times 4}\right) k^{\prime 4}-\cdots \\
& -\frac{\mathbf{r}^{2}}{2^{2}} \cdot \frac{3^{2}}{4^{2}} \cdots \frac{(2 n-3)^{2}}{(2 n-2)^{2}} \frac{(2 n-1)}{2 n}\left[\frac{2}{1 \times 2}+\frac{2}{3 \times 4}+\cdot \cdot\right. \\
& \left.+\frac{2}{(2 n-3)(2 n-2)}+\frac{1}{(2 n-1) 2 n}\right] k^{\prime 2 n}+\cdots \\
& =\sum_{n=0}^{\infty} \frac{(\mid 2 n)^{2} k^{\prime 2 n}}{2^{4 n}(\mid n)^{4}}\left[\frac{n}{2 n-1} \log n \frac{16}{k^{\prime 2}}+\frac{1}{(2 n-1)^{2}}\right. \\
& \left.-\frac{(2 n+\mathrm{I}) k^{\prime 2}}{2(n+\mathrm{I})} \sum_{s=0}^{n} \frac{\mathrm{I}}{(s+\mathrm{I})(2 s+\mathrm{I})}\right]
\end{aligned}
$$

Substituting these values in equation (I0)

$$
\begin{aligned}
M= & \pi r_{1}\left[( \operatorname { l o g } \frac { \mathrm { I } 6 } { k ^ { \prime 2 } } ) \left\{\mathrm{I}+\frac{\mathrm{I}}{2^{2}} k^{\prime 2}+\frac{\mathrm{I}}{2^{2}} \cdot \frac{\mathrm{I}^{2}}{4^{2}} k^{\prime 4}+\frac{\mathrm{I}}{2^{2}} \cdot \frac{\mathrm{I}^{2}}{4^{2}} \cdot \frac{3^{2}}{6^{2}} k^{\prime 6}+\cdots\right.\right. \\
& \left.\quad+\frac{\mathrm{I}}{2^{2}} \cdot \frac{\mathrm{I}^{2}}{4^{2}} \cdot \frac{3^{2}}{6^{2}} \cdots \frac{(2 n-3)^{2}}{(2 n)^{2}} k^{\prime 2 \mathrm{n}}+\cdots\right\} \\
& -2\left\{2-\frac{k^{\prime 2}}{4}+\frac{\mathrm{I}}{2^{2}} \cdot \frac{\mathrm{I}^{2}}{4^{2}}\left(\frac{2}{\mathrm{I} \times 2}-\frac{\mathrm{I}}{2}\right) k^{\prime 4}+\frac{\mathrm{I}}{2^{2}} \cdot \frac{\mathrm{I}^{2}}{4^{2}} \cdot \frac{3^{2}}{6^{2}}\left(\frac{2}{\mathrm{I} \times 2}+\frac{2}{3 \times 4}-\frac{2}{6}\right) k^{\prime 6}\right. \\
& +\cdots+\frac{\mathrm{I}}{2^{2}} \cdot \frac{\mathrm{I}^{2}}{4^{2}} \cdot \frac{3^{2}}{6^{2}} \cdots \frac{(2 n-3)^{2}}{(2 n)^{2}}\left(\frac{2}{\mathrm{I} \times 2}+\frac{2}{3 \times 4}+\cdots\right. \\
= & \left.\left.\pi r_{1} \sum_{n=0}^{\infty} \frac{(\mid 2 n)^{2} k^{\prime 2 \mathrm{n}}}{2^{4 \mathrm{n}}(\mid n)^{4}}\left[\frac{\mathrm{I}}{(2 n-3)(2 n-2)}-\frac{2}{2 n}\right) k^{\prime 2 \mathrm{n}}+\cdots\right\}\right] \\
\quad & \left.+\frac{2 k^{\prime 2}}{(n+\mathrm{I})(2 n+\mathrm{I})}-\frac{k^{\prime 2}}{2(n+\mathrm{I})^{2}} \sum_{s=0}^{n} \frac{\mathrm{I} 6}{(s+\mathrm{I})(2 s+\mathrm{I})}\right] \\
= & \left.r_{1} H \quad \frac{4}{(2 n-\mathrm{I})^{2}}\right]
\end{aligned}
$$


where $H$ is a function ${ }^{8}$ of $k^{\prime 2}$ and hence of $k^{2}$. This formula can be used for values of $k^{\prime 2}$ from o to 0.7 , provided a large number of terms are used. When $k^{\prime 2}$ is small $\operatorname{logn} \frac{\mathrm{I}}{k^{\prime 2}}$ becomes large, and the summation depends almost entirely on the value of this logarithm. Hence, in this region $H$ is nearly proportional to colog $k^{\prime 2}$.

The mutual inductance of any two coaxial circles can be computed either by formula (13) or (16). If $k^{2}$ is less than 0.4 $\left(k^{\prime 2}\right.$ greater than 0.6$)$ equation (13) should be used. For larger values of $k^{2}$ use equation (I6).

By writing the coefficients of the powers of $k$ and $k^{\prime}$ as decimals, the above equations are in much more convenient form for computation. Equation (13) becomes

$$
\frac{M}{r_{1}}=\mathrm{I} .23370 k^{4} \mid \begin{aligned}
& 1.00000 \\
& +.75000 k^{2} \\
& +.58594 k^{4} \\
& +.47852 k^{6} \\
& +.40375 k^{8} \\
& +.34895 k^{10} \\
& +.30715 k^{12} \\
& +.27424 k^{14} \\
& +.24767 k^{16} \\
& +.22578 k^{18} \\
& +.20744 k^{20} \\
& + \\
& . \\
& .
\end{aligned}
$$

8 Formula (16) is equivalent to Butterworth's formula $D$ given in Phil. Mag. 31, p. 276; r9r6. It is given as formula $(4 \mathrm{~A})$ in Grover's collection, B. S. Bull. 14, p. 540 . B. S. Sci. Paper No. 320. 
Writing all numerics as decimals, equation (I6) becomes $\frac{M}{r_{1}}=\left[8.71035+7.23378 \operatorname{colog} k^{\prime 2}\right]$

$$
\begin{aligned}
& 1.00000-\pi \mid 4.00000 \\
& +.25000 k^{\prime 2} \quad-.50000 k^{\prime 2} \\
& +.01562 k^{\prime 4}+\text {. OI562 } k^{\prime 4} \\
& +.00391 k^{\prime 6} \quad+.00651 k^{\prime 6} \\
& +.00153 k^{18}+.00300 k^{18} \\
& +.00075 k^{10} \quad+.00160 k^{10} \\
& +.00042 k^{12}+.00094 k^{12} \\
& +.00026 k^{14}+.00060 k^{14} \\
& +.00017 k^{16}+.00040 k^{16} \\
& +.00012 k^{18}+.00027 k^{18} \text { (18) } \\
& +.00008 k^{20}+.00020 k^{20} \\
& +.00006 k^{22}+.00015 k^{22} \\
& +.00005 k^{24}+\text {. } 000 \text { I I } k^{\prime 24} \\
& +.00004 k^{26}++.00009 k^{26} \\
& +.00003 k^{\prime 28}++.00007 k^{28} \\
& +.00002 k^{\prime 30}+.00006 k^{30} \\
& + \\
& +
\end{aligned}
$$

It is only in the middle range of values of $k$ and $k^{\prime}$ that the large number of terms given above will be required, and then only when extreme accuracy is desired.

The principal use of these formulas is to compute the constants of Table $\mathrm{I}$. This table permits the computation of an inductance with an accuracy of one-tenth per cent, and its use is much simpler than that of either of the above formulas. It is only when higher precision is required that it is necessary to resort to either formula (I 7 ) or (I 8 ).

\section{FORMULAS INVOLVING ONLY THE RADII OF THE COILS AND THE DISTANCE BETWEEN THEM}

Formulas can be derived which give the mutual inductance as an algebraic function of the measured dimensions. Such formulas are suitable for computation in all cases, except when the coils are close together. These formulas, while in themselves quite complicated, permit the computation of tables from which the mutual inductance can easily be determined. 


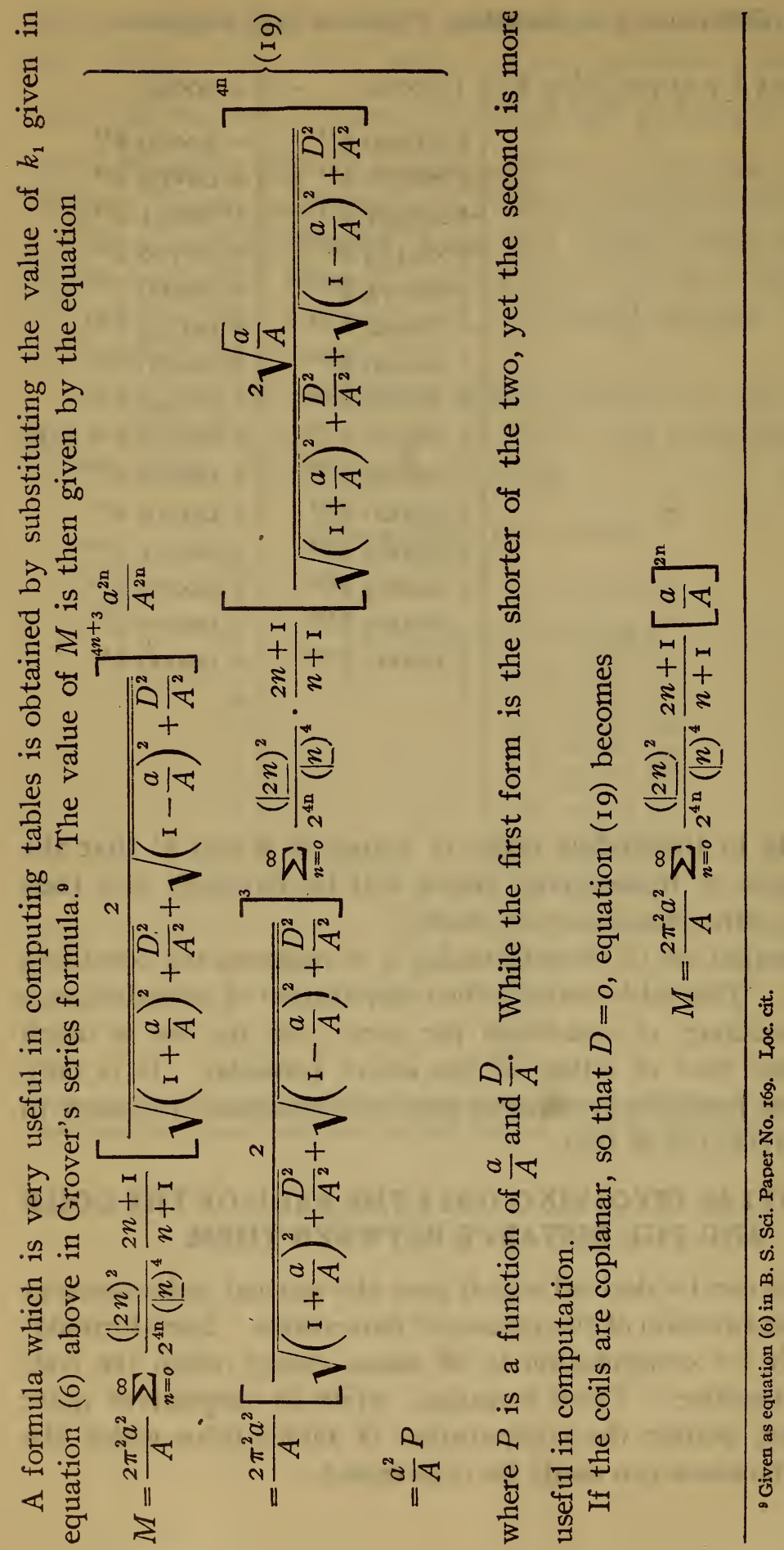


By putting all the numerics in the form of decimals, this equation can be written:

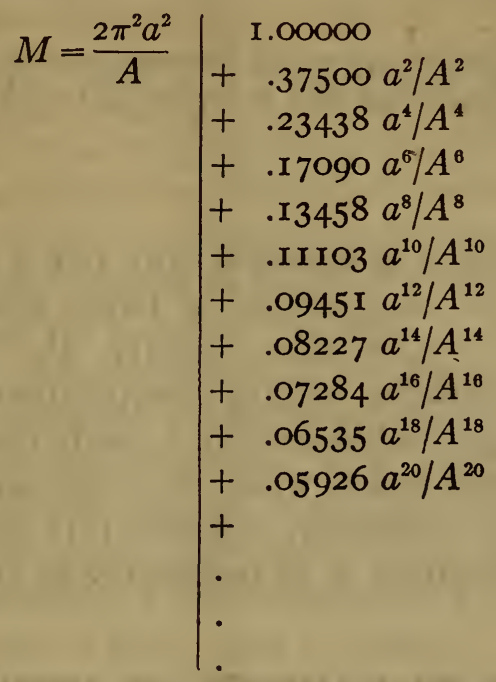

The numerics of this equation apply also to equation (19) and can advantageously be used when it is necessary to compute by that formula. Equation (Ig) is convergent for all values of $D$, except when $a=A$ and $D=o$. It converges very rapidly when $\frac{D}{A}$ is large relative to $\frac{a}{A}$. In general, it may be said that by means of this formula the mutual inductance between any two coaxial circles can be computed. However, when the circles are close together, the convergence is so slow that the computation is very laborious. When the shortest distance between the circumferences is greater than one-third of the radius of the larger circle, an accuracy greater than I part in 10,000 will be obtained if the first I I terms of the series are used. When the distance between the centers is greater than the radius of the larger circle, the same accuracy can be obtained by using the first 3 terms of the series.

Since equation (20) is convergent when $a<A$ and when $a=A$ if $D \neq 0$, it can be used in mathematical derivations where it is necessary to have a formula for the mutual inductance which is applicable to a wide range of circles. For example, it should be possible by means of this formula to compute the skin effect in a circular ring by the integral-equation method. Whether the resulting formula will be sufficiently convergent for practical use can not be predicted. 
If $D$ is large relative to $A$, then by substituting the value of $k_{1}$ given as equation (7) above in Grover's series formula

$$
\begin{aligned}
M & =\frac{2 \pi^{2} a^{2} A^{2}}{D^{3}} \sum_{n=0}^{\infty} \frac{(\mid 2 n)^{2}}{2^{4 n}(\underline{1 n})^{4}} \cdot \frac{2 n+\mathrm{r}}{n+\mathrm{r}}\left[\frac{2}{\sqrt{\mathrm{I}+\frac{A^{2}}{D^{2}}\left(\mathrm{I}+\frac{a}{A}\right)^{2}+\sqrt{\mathrm{I}+\frac{A^{2}}{D^{2}}\left(\mathrm{I}-\frac{a}{A}\right)^{2}}}}\right]^{4 n+3} \frac{a^{2 \mathrm{n}}}{A^{2 \mathrm{n}}} \cdot \frac{A^{4 \mathrm{n}}}{D^{4 \mathrm{n}}} \\
& =\frac{a^{2} A^{2} S}{D^{3}} S
\end{aligned}
$$

Equation (2I) is the same as equation ( $\mathrm{r} 9$ ), but is written in a form which simplifies the construction of tables when the coils are far apart. When $D$ approaches infinity, the value of $P$ approaches zero asymptotically, making interpolation impossible, whereas the value of $S$ approaches unity in a nearly linear manner. Hence, to facilitate computation when the coils are far apart, tables of $S$ are desirable. However, equation (2I) should not be used for the direct computation of an inductance as ( 19 ) is equivalent and simpler.

\section{USE OF TABLES TO COMPUTE AN INDUCTANCE}

Two different types of tables are given at the end of this paper, each one of which permits the calculation of the mutual inductance of any two coaxial circles. In the first type (Tables $\mathrm{x}, 2$, and 3 ) there is a single parameter which must be determined from the measured dimensions. In the second type (Tables 6,7 , and 8 ) there are two parameters which come directly from the measured dimensions. In both types of tables the parameters have been chosen so that the interpolation is approximately linear, thus reducing the work involved in making a computation and increasing the accuracy of the result. In the first type of table the parameter is a function of $k$ or $k^{\prime}$. The size of the tables for a given accuracy can be decidedly reduced by choosing different parameters for different ranges of $k$. For this reason three tables have been constructed.

In Table $\mathrm{r}$, values of $\frac{M}{r_{1}}$ are given as a function of $k^{2}$ (or $k^{\prime 2}$ ) throughout the entire range of values. However, for the ranges $k^{2}=0$ to $k^{2}=0 . I$ and $k^{2}=0.85$ to $k^{2}=\mathrm{I}$, the values of $\frac{M}{r_{1}}$ are changing so'rapidly that interpolation is not accurate. For the region $k^{2}=0.85$ to $k^{2}=1.0\left(k^{\prime 2}=0.15\right.$ to $\left.k^{\prime 2}=0\right)$; that is, when the coils are close together, Table 2 will give the necessary accuracy. If $k^{2}$ is less than o.r; that is, if the coils are far apart, Table 3 should be used. 
To compute the inductance of any two coaxial circles by these tables, the following procedure should be followed: From the measured dimensions compute $r_{1}$ and $k^{2}$. Values of $k^{2}$ in terms of the ratios of dimensions are given in Tables 4 and 5 . If the value of $k^{2}$ lies between o.I and 0.85 , find the values of $H$ from Table $\mathrm{I}$. If $k^{2}$ is greater than 0.85 , then find the cologarithm of $k^{\prime 2}$ and use this as the parameter in Table 2 to obtain $H$. However, if $k^{2}$ is less than o.I, find $k^{4}$ and determine the value of $H$ from Table 3 .

It is generally simpler to compute the inductance directly from the dimensions by means of Tables 6,7 , and 8 . This avoids the necessity of computing the auxiliary constants $r_{1}$ and $k^{2}$. Table 6 gives the values when the distance between the circles is less than the radius of the larger circle, Table 7 when the distance between the circles is greater than the radius of the larger circle but less than three times the radius, and Table 8 when the distance between the circles is more than 2.2 times the radius of the larger circle. There is a region where Tables 7 and 8 overlap. In this region computation is simpler by Table 7 , but Table 8 gives the greater accuracy.

If the mutual inductance is sought for circles of which the values of the parameters are not those given in the tables, a double interpolation will be necessary. Since the interpolation is approximately linear in both directions, it is only necessary to add to the tabular value the sum of the horizontal and vertical interpolation.

In general, the tables are constructed so that an accuracy of onetenth per cent can be obtained in the most unfavorable case of interpolation. Where that was not feasible, the tabular differences have been omitted.

\section{DETERMINATION OF COAXIAL CIRCLES TO HAVE A DESIRED MUTUAL INDUCTANCE}

In designing apparatus it is often necessary to determine the diameter and distance apart of two circles to have a predetermined inductance. This can readily be done by either set of tables or by the charts.

In using the first set of tables, a value of $A$ must first be chosen. If it is desired to have the coils close together, the value of $\frac{M}{2 A}$ must be large, while if they are to be far apart the value must be small. Ordinarily a value of $\frac{M}{2 A}$ between 4 .o and o. I should be chosen.

Then since one value of $r_{1}$ is $2 A$, one value of $H$ is found by dividing $M$ by $2 A$. To avoid interpolation, select in the proper 
table a value of $H$, which is near the value of $\frac{M}{2 A}$, and read the corresponding value of $k^{2}$.

Then $r_{1}=\frac{M}{H}$. By equation (3)

and by equation (I)

$$
a=\frac{k^{2} r_{1}^{2}}{4 A}
$$

$$
D=\sqrt{r_{1}^{2}-(A+a)^{2}}
$$

If the above does not give a suitable size and location for the second circle, other values can readily be determined. Suppose that it is desired to have the second circle larger than that given above. Select a value of $H$ which is Io or 20 per cent smaller than the one which was first used and compute the values of $a$ and $D$. Should the value of $D$ be imaginary, then too small a value of $H$ has been chosen.

If it is desired to have the second circle of smaller radius than that given by the first computation, then the value of $H$ must be chosen which is larger than the one which was first used. The procedure is then the same as that outlined above. A few trials will give the desired size and location of the second circle.

If the relative size of the coils and distance between them are given, then Tables 6,7 , and 8 can be used advantageously to determine the absolute size to give a desired mutual inductance. If $\frac{D}{A}$ is less than three, the value of $P$ can be found from Table 6 or Table 7 . Then $a=\frac{M}{P} \cdot \frac{A}{a}$, and the values of $A$ and $D$ can be computed from the ratios initially given. If $\frac{D}{A}$ is greater than three, the value of $S$ can be found from Table 8 . Then

$$
D=\frac{M}{S} \cdot \frac{A^{2}}{a^{2}} \cdot \frac{D^{4}}{A^{4}}
$$

In many cases this method will be simpler than that by the use of Table $\mathrm{I}$.

\section{USE OF CHARTS}

Three charts (figs. 2, 3, and 4) have been prepared which are useful when approximate solutions of problems connected with the mutual inductance of coaxial circles are sufficient. As three 


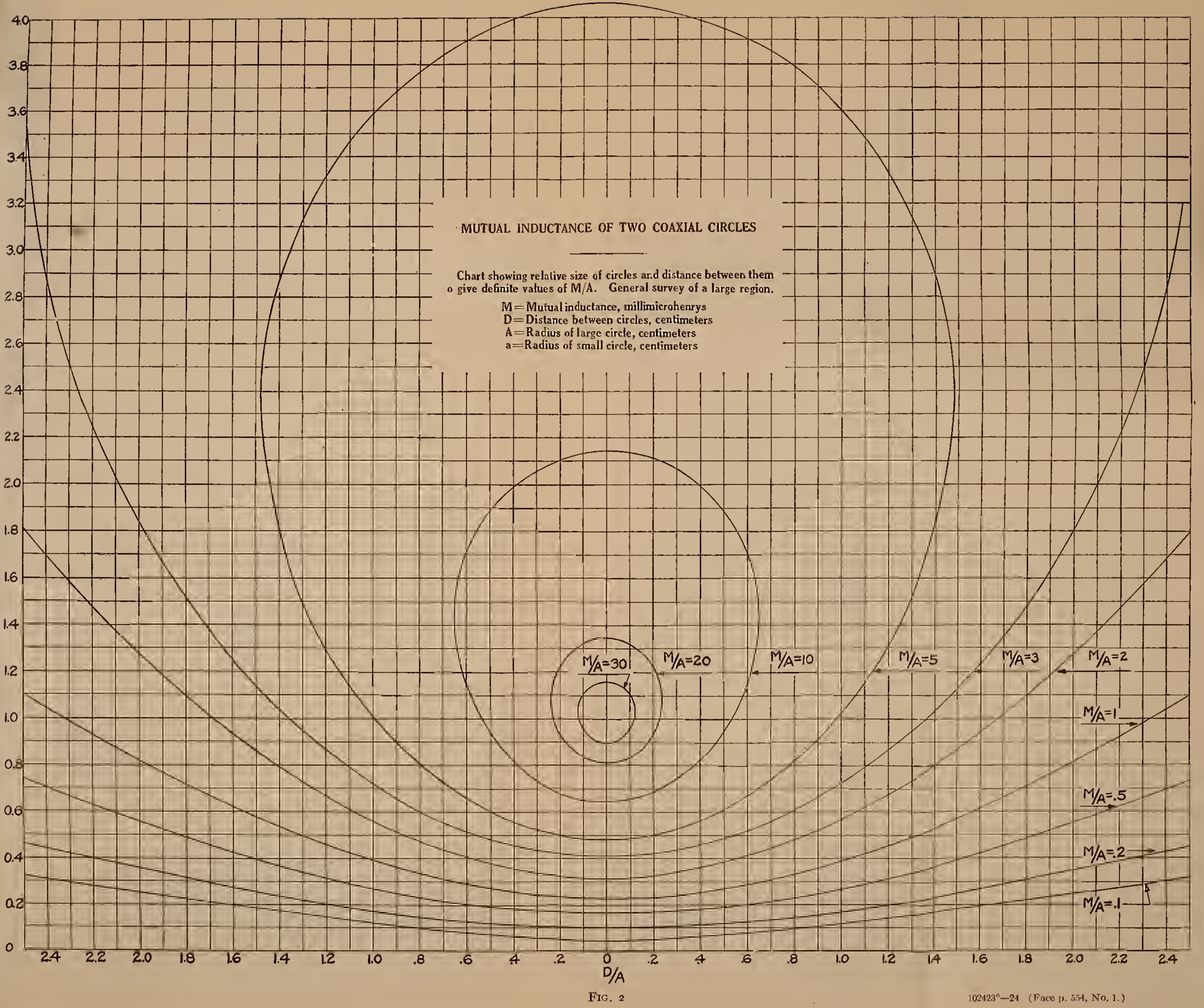


MUTUAL INDUCTANCE OF TWO COAXIAL CIRCLES

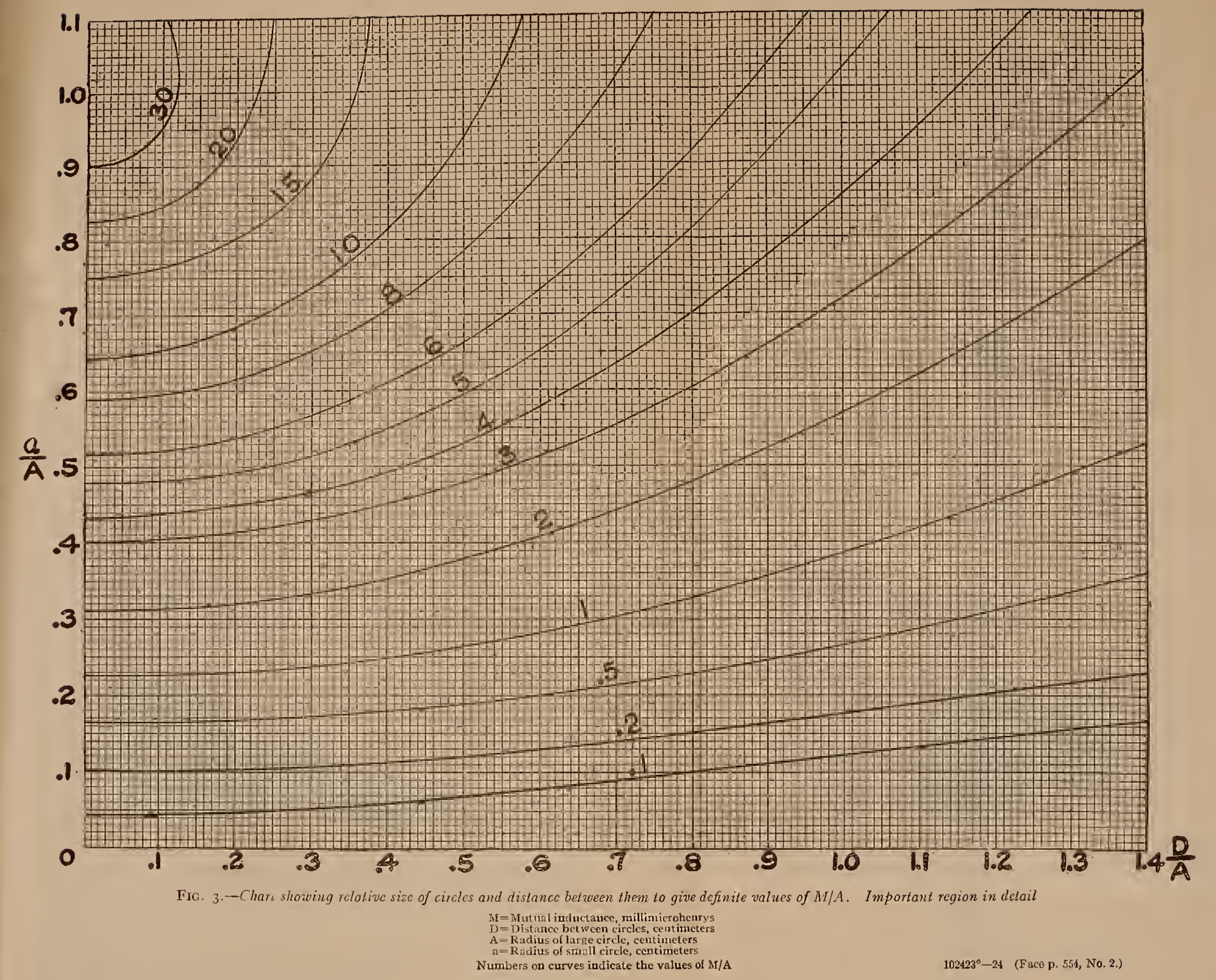




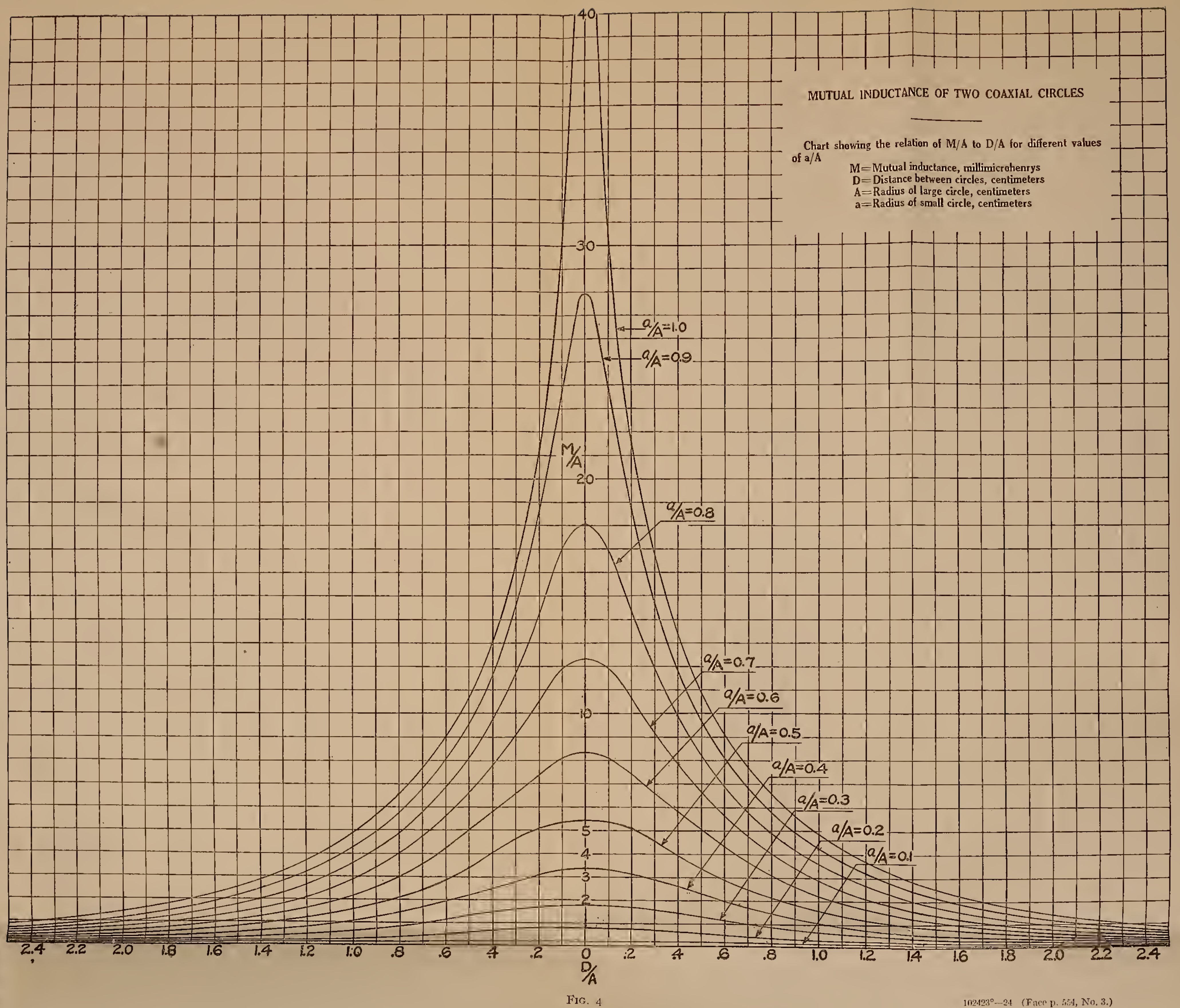


coordinates are necessary to completely represent this function, it is only possible on plane coordinate paper to plot contour lines which show the curves of two of the variables when the third has a definite numerical value. In the first two charts (figs. 2 and 3), definite values of $\frac{M}{A}$ are chosen, and curves given for $\frac{a}{A}$ as ordinate, and $\frac{D}{A}$ as abscissa. The only difference between these charts is that the second (fig. 3) covers a smaller region with a larger scale than does the first. The third chart (fig. 4) gives the curves of $\frac{M}{A}$ as ordinate and $\frac{D}{A}$ as abscissa for definite values of $\frac{\alpha}{A}$.

To determine the mutual inductance of given coils, the third chart (fig. 4) should be used. Should the value of $\frac{a}{A}$ be that for which a curve is plotted, then the value of $\frac{M}{A}$ for the given value of $\frac{D}{A}$ can be read quite accurately. In case it is necessary to interpolate between the curves, the accuracy will be considerably reduced.

To determine the size of circles and distance between them to give a desired mutual inductance, the first and second charts (figs. 2 and 3 ) are useful. In these charts the curves correspond to the lines of magnetic force ${ }^{10}$ around a circle, the center of which coincides with the origin, the plane of which is perpendicular to the $\mathrm{X}$ axis, and the radius of which is unity. Since the mutual inductance depends on the number of lines of magnetic force from the first circle which cuts the second, the curves show the different sizes and positions that the second circle can have to give a single value of the mutual inductance. Another way of visualizing this is to consider that the diagram is so reduced in scale that the distance $\frac{a}{A}=\mathrm{I}$ is $\mathrm{I} \mathrm{cm}$. Then if one circle has its center at the origin, its plane perpendicular to the axis, and its radius equal to $\mathrm{I} \mathrm{cm}$; and if the second circle, having its center on the $\mathrm{X}$ axis, has the point where its circumference cuts the paper coincident with one of the curves, then the ordinate and abscissa of this point give the radius of the circle and the

${ }^{10}$ Such a set of curves without any numerical values is given as Fig. $x 8$ in Maxwell's Electricity and Magnetism, 2.

$102423^{\circ}-24-3$ 
distance between the circles, respectively, while the value of mutual inductance in millimicrohenrys is given by the value of $\frac{M}{A}$ on the curve.

To use this chart for determining the size and distance of two circles to give a desired mutual inductance, it is first necessary to choose the radius $A$ of one of the circles which will be used. It is desirable to choose this value of $A$ so that $\frac{M}{A}$ is one of the values for which a curve is given in the charts (figs. 2 or 3.) Then by selecting various points on the curve, a series of values of $\frac{D}{A}$ and the corresponding values $\frac{a}{A}$ can be obtained, any pair of which will give the desired mutual inductance. If an additional condition is imposed, such, for example, as requiring that the circles shall have the same radii $(A=a)$, or that the circles shall lie in the same plane $(D=0)$, then there are only one pair of values for $\frac{D}{A}$ and $\frac{a}{A}$.

If it is desired to design an inductance in which the radii of the two circles shall have a definite ratio, then the third chart (fig. 4) can be used advantageously. For example, if the circles are to be of equal size, $\frac{a}{A}=\mathrm{I}$, then from the curve so labeled a series of values for $\frac{M}{A}$ and the corresponding values of $\frac{D}{A}$ can be determined. This chart is especially useful where the relative dimensions are known. Then if $\frac{a}{A}$ is one of the values for which a curve is plotted, the value of $\frac{M}{A}$ is read directly from the chart.

\section{MUTUAL INDUCTANCE OF COAXIAL COILS}

All the formulas for the mutual inductance of coaxial coils are based on the mutual inductance of two coaxial circles, the radii of which are the mean radii of the coils, and the centers of which coincide with the centers of the coils. If the breadth and depth of the coils are small relative to their mean radii and to the distance between them, then

$$
M=n_{1} n_{2} M_{\text {o }}
$$


where $M$ is the mutual inductance between the coils, $M_{\mathrm{o}}$ the mutual inductance between two coaxial circles at the center of the coils, and $n_{1}$ and $n_{2}$ the number of turns in the two coils, respectively. In this case, all the methods of computation and design which have been given under coaxial circles can be adapted to use with coils by a proper use of the factor $n_{1} n_{2}$.

If the coils are close together, or if their radii are small, correction terms need to be applied ${ }^{11}$ to the above formula. No simple method of applying these corrections has yet been developed.

\section{EXAMPLES OF USE OF CHARTS, TABLES, AND FORMULAS}

To illustrate the use of the tables, charts, and formulas, examples will be selected from those given by Rosa and Grover, ${ }^{12}$ who have given the results correct to about I part in $\mathrm{I}, 000,000$. For each example, there will, in general, be five solutions by the methods given in this paper, viz, one by the charts, two by tables, and two by formulas. However, the charts can not be used when the circumferences are close together, or when the distance between the coils is great. The second set of tables (Tables 6, 7, and 8) will not give values when the circumferences are close together, and under the same condition the formula-equation (18)-giving the mutual inductance in terms of the measured dimensions is not sufficiently convergent to be practical. Hence, when the circumferences are close together, only two values can be obtained, and when they are far apart only four values.

EXAMPLE 1

Measured dimensions:

$$
A=a=25 \mathrm{~cm} \quad D=20 \mathrm{~cm}
$$

Computed constants:

$$
\begin{array}{llrl}
r_{1}{ }_{1} & =2,900 & r_{1} & =53.85 \mathrm{I} 6 \\
r_{2}^{2} & =400 & r_{2} & =20.000 \\
k^{2} & =0.862069 & k^{\prime 2} & =0.13793 \mathrm{I} \\
\frac{a}{A} & =\mathrm{I} & \frac{D}{A} & =0.8
\end{array}
$$

Rosa and Grover value of mutual inductance is 167.0856 millimicrohenrys. 
(a) Value of Mutual Inductance from the Charts.On chart 3 (fig. 4) the value of $\frac{M}{A}$, read from the curve $\frac{a}{A}=\mathrm{I}$, when

$$
\frac{D}{A}=0.8, \text { is } 6.7
$$

Hence

$$
M=168 \text { millimicrohenrys }
$$

The error is less than I per cent.

(b) VALUE OF $M$ From TABLES Using $k^{2}$ AS A PARAMETER.By interpolating in Table $4, k^{2}=0.8622$. Using this value, the value of $H$ from Table $\mathrm{I}$ is 3.103 .

$$
\therefore M=r_{1} H=\text { I67.I millimicrohenrys }
$$

This result is in error by less than one-tenth of $\mathrm{I}$ per cent. The same result would have been obtained had a more accurate value of $k^{2}$ been used.

(c) Computation from Tables which Use Only the Ratio of THE Dimensions.-Interpolating in Table $6, P=6.700$

$$
\therefore M=\frac{a^{2}}{A} P=167.5 \text { millimicrohenrys }
$$

This is in error by a little over two-tenths of I per cent.

(d) Computation by Formula (I8) Involving $k^{2}$.-Substituting in equation (I8)

$$
\begin{aligned}
& \frac{M}{53.8516}=[8.71035+7.23378 \times 0.860335] \mid \begin{array}{l|r}
1.00000-\pi & 4.00000 \\
+.03448 & -.06897 \\
+.00030 & +.00030 \\
+.0000 \mathrm{I} & +.0000 \mathrm{I}
\end{array} \\
& =\mathrm{I} 4.93382 \times \mathrm{I} .03479-3 . \mathrm{I} 4 \mathrm{I} 59 \times 3.93 \mathrm{I} 35 \\
& \therefore M=167.082
\end{aligned}
$$

In this case only four terms were necessary to give the values of the series to within I part in 100,000. However, as the result is the difference of two quantities which have values nearly alike, the result is not known with that accuracy. This computed result differs from the correct result by less than 3 parts in 100,000 . 
(e) Computation By a Formula which Invol,ves Only the MEASURED DImEnsions.-Equation ( $\mathrm{r} g$ ) is suitable for this computation.

$$
\begin{aligned}
M=2 \pi^{2} \cdot 25 \cdot[0.67703]^{3} \cdot \mid \begin{array}{l}
1.00000 \\
+.07879 \\
+.01035 \\
+.00158 \\
+.00026 \\
+.00005 \\
+.00001
\end{array} \\
=493.48 \times 0.31033 \times 1.09104 \\
=167.085
\end{aligned}
$$

This result is correct to within I part in 100,000. The convergence of the series is such that no difficulty would be experienced in obtaining a higher accuracy if desired.

Measured dimensions:

\section{EXAMPLE 2 .}

$$
A=a=25 \mathrm{~cm} \quad D=\mathrm{I} \mathrm{cm}
$$

Computed constants:

$$
\begin{array}{ll}
r^{2}=2,501 & r_{1}=50.0100 \\
r_{2}^{2}=\mathrm{I} & r_{2}=\mathrm{I} . \\
k^{\prime 2}=\frac{r_{2}{ }_{2}}{r^{2}}=0.000399840 &
\end{array}
$$

Rosa and Grover value of mutual inductance is 1036.666 millimicrohenrys.

(a) Value from Charts.-From the third chart (fig. 4), $\frac{M}{A}$ is approximately 40 , but the curve is changing so rapidly at this point that the value is little more than an estimate. This gives

$$
M=\mathrm{I}, \mathrm{O} 0 \mathrm{O} \text { millimicrohenrys }
$$

which is in error by nearly 4 per cent.

(b) VALUE FROM TABLE IN $k^{\prime 2}$. W With coils so close together it is impossible to obtain $k^{\prime 2}$ with sufficient accuracy from Table 4. Using the value of $k^{\prime 2}$ given above

From Table 2

$$
\begin{aligned}
\operatorname{colog} k^{2} & =3.398 \mathrm{I} \\
H & =20.728 \\
\therefore M & =\mathrm{I}, 036.6
\end{aligned}
$$

This is in error by less than I part in I0,000. 
(c) Computation by Tables in $\frac{a}{A}$ AND $\frac{D}{A}$. -Table 6 can not be used when the coils are so close together.

(d) Computation by a Formula Involving $k^{\prime 2}$.-Using formula (I 8)

$$
\begin{aligned}
\frac{M}{r_{1}} & =[8.71035+7.23378 \times 3.39811]|+.00000-\pi| \begin{array}{r}
4.00000 \\
\\
\end{array}=33.29489 \times 1.0001-\pi \times 3.99980
\end{aligned}
$$

$\therefore M=\mathrm{I}, 036.665$

This formula is especially well suited to this example. Only two terms are required in the series, yet the result is accurate to I part in $1,000,000$.

(e) Computation From Measured Dimensions.-For these constants, equation (19) is not sufficiently convergent to make the computation practicable.

\section{EXAMPLE 3}

Measured dimensions:

$$
A=a=\text { Io } \quad D=100
$$

Computed constants:

$$
\begin{aligned}
r^{2} & =10,400 & & r_{1}=101.980 \\
k^{2} & =0.0384615 & & D \\
\frac{a}{A} & =\mathrm{I} & & \mathrm{IO}
\end{aligned}
$$

Rosa and Grover value of mutual inductance is o.1916496 millimicrohenrys.

(a) VALUE OF CHART.-Value of $\frac{D}{A}$ beyond range of chart.

(b) VALUE FROM TABLE IN $k^{2}$.-With coils so far apart, it is impossible to obtain $k^{2}$ with sufficient accuracy from Table 5 . Using value of $k^{2}$ computed above

From Table 3

$$
\begin{aligned}
k^{4} & =0.001479 \\
H & =0.001881
\end{aligned}
$$$$
\therefore M=0.1918 \text { millimicrohenry }
$$

This is in error less than one-tenth of I per cent.

(c) Values from Table Using Raitio of Dimensions.From Table 8

$$
\begin{aligned}
& S=19.18 \\
& \therefore M=\frac{{\overline{\mathrm{IO}^{2}} \times \overline{\mathrm{IO}}^{2}}_{\mathrm{IOO}^{3}}}{19.18} \\
& =0.1918 \text { millimicrohenry }
\end{aligned}
$$

The error is less than a tenth of I per cent. 
(d) Computation by a Formula in $k^{2}$.-By equation ( 17 )

$$
\begin{aligned}
& \frac{M}{r_{1}}=\mathrm{I} .23370 \times 0.00147929 \mid \begin{array}{r}
\mathrm{I} .00000 \\
+.02885 \\
+.00087 \\
+.00003
\end{array} \\
& M=0.191650
\end{aligned}
$$

The error is less than I part in 100,000.

(e) Computation BY a Formula InVOlving MEASURED Dimensions.-Equation ( $\mathrm{r} 9$ ) is suitable for this example.

$$
\begin{aligned}
M & =20 \pi^{2}[0.0990195]^{3} \mid \begin{array}{r}
1.000000 \\
+.000036
\end{array} \\
& =0.191649
\end{aligned}
$$

This result is in error by only 2 parts in $1,000,000$. It has been carried to this accuracy to show the ease of computing by this formula when the coils are far apart.

\section{SUMMARY}

Charts are given from which the mutual inductance of two coaxial circles can be read. Under favorable conditions the result will not be in error by as much as I per cent. These charts are also useful for designers.

Tables are given by means of which the computation of the mutual inductance of any two coaxial circles with an accuracy of o.I per cent is easily accomplished. These tables can also be used for the inverse problem of finding two circles which will give a desired inductance.

Formulas are given by means of which the mutual inductance of any two coaxial circles can be computed with an accuracy of o.or per cent. The coefficients of the terms in these formulas are expressed in decimal form, and they are so arranged that the labor of computation is reduced to a minimum. When the coils are either close together or far apart, these formulas can be used to give an accuracy even greater than o.or per cent. In the intermediate range the number of terms required to give an accuracy of even I part in 100,000 is very large. For this range, Nagaoka's formula ${ }^{13}$ is very convenient, especially if the tables of Nagaoka and Sakurai ${ }^{13}$ of $k^{2}$ are available.

The authors wish to acknowledge assistance from a number of their associates. In particular, Dr. Chester Snow has aided in simplifying the mathematical expressions.

WASHINGTON, April 14, 1924.

13 Given as equation ( 8 ) in Rosa and Grover's paper. 


\section{APPENDIX}

\section{TABLES AND CHARTS FOR DETERMINING THE MUTUAL INDUC- TANCE OF COAXIAL CIRCLES}

Two types of tables are given in this appendix, namely, single entry tables and double entry tables. In the single entry tables the parameter $\left(k^{2}, \operatorname{colog} k^{\prime 2}\right.$, or $\left.k^{4}\right)$ is a somewhat complicated function of the measured dimensions (the radii of the circles and the distance between their centers). In the double entry tables each parameter is either the ratio of two measured dimensions or the square of such a ratio. Hence the parameters for the double entry tables are much more easily determined than are those for the single entry tables. However, the interpolation in the double entry tables is more difficult than with the single entry tables.

So far as possible the tables have been constructed so as to give an accuracy of one-tenth of I per cent in the value of the computed mutual inductance. However, when it is necessary to determine the inductance with this accuracy, it is suggested that computations be made by both types of tables. Should they fail to check with the required accuracy a third computation should be made, using one of the formulas given in the text.

\section{TABLE 1.-Values of $H$ in the Equation $M=r_{1} H$}

Method of Using TABLE To Compute AN Inductance.-Given $A$ and $a$, the radii of two coaxial circles, and $D$, the distance between their centers. Compute

and

$$
k^{2}=\frac{4 A a}{(A+a)^{2}+D^{2}}
$$

$$
r_{1}=\sqrt{(A+a)^{2}+D^{2}}
$$

If the value of $k^{2}$ lies between 0.1 and 0.85 , obtain the value of $H$ from this table, using linear interpolation if necessary. Then $M=r_{1} H$.

Method of Using Table to Find Size and Position of Circles which Wril Give A DESIRED Inductance.-Choose a value for $A$. Select a value of $H$ near the value given by $\frac{M}{2 A}$, for which a value of $k^{2}$ is given in the table. Then

$$
\begin{aligned}
& r_{1}=\frac{M}{H} \\
& a=\frac{k^{2} r_{1}}{4 A} \\
& D=\sqrt{r^{2}{ }_{1}-(A+a)^{2}}
\end{aligned}
$$

If $D$ is imaginary, the value of $H$ has been taken too far from the value given by $\frac{M}{2 A}$.

UNITS.-Values of $A, a$, and $D$ are in centimeters. Value of $M$ in millimicrohenrys. If $A, a$, and $D$ are in inches, multiply the value of $H$ by 2.54 to give $M$ in millimicrohenrys (thousandths of a microhenry).

ACCURACY.-For values of $k^{2}$ between 0.Io and 0.85 , values of $H$ accurate to onetenth of I per cent can be obtained by linear interpolation. 


\begin{tabular}{|c|c|c|c|c|c|c|c|}
\hline$k^{2}$ & $H$ & Difference & $k^{\prime 2}$ & $k^{2}$ & $H$ & Difference & $k^{\prime 2}$ \\
\hline $\begin{array}{l}0 \\
.01 \\
.02 \\
.03 \\
.04\end{array}$ & $\begin{array}{l}0 \\
.0001243 \\
.0005010 \\
.001136 \\
.002035\end{array}$ & $\begin{array}{c}0.0001243 \\
.0003767 \\
.000635 \\
.000899 \\
.001170\end{array}$ & $\begin{array}{r}1.00 \\
.99 \\
.98 \\
.97 \\
.96\end{array}$ & $\begin{array}{l}0.50 \\
.51 \\
.52 \\
.53 \\
.54\end{array}$ & $\begin{array}{r}0.5016 \\
.5287 \\
.5571 \\
.5866 \\
.6175\end{array}$ & $\begin{array}{r}0.0271 \\
.0284 \\
.0295 \\
.0309 \\
.0321\end{array}$ & $\begin{array}{l}0.50 \\
.49 \\
.48 \\
.47 \\
.46\end{array}$ \\
\hline $\begin{array}{l}.05 \\
.06 \\
.07 \\
.08 \\
.09\end{array}$ & $\begin{array}{l}.003205 \\
.004651 \\
.006381 \\
.008401 \\
.01072\end{array}$ & $\begin{array}{l}.001446 \\
.001730 \\
.002020 \\
.00232 \\
.00262\end{array}$ & $\begin{array}{l}.95 \\
.94 \\
.93 \\
.92 \\
.91\end{array}$ & $\begin{array}{l}.55 \\
.56 \\
.57 \\
.58 \\
.59\end{array}$ & $\begin{array}{l}.6496 \\
.6832 \\
.7182 \\
.7548 \\
.7929\end{array}$ & $\begin{array}{l}.0336 \\
.0350 \\
.0366 \\
.0381 \\
.0399\end{array}$ & $\begin{array}{l}.45 \\
.44 \\
.43 \\
.42 \\
.41\end{array}$ \\
\hline $\begin{array}{l}.10 \\
.11 \\
.12 \\
.13 \\
.14\end{array}$ & $\begin{array}{l}.01334 \\
.01628 \\
.01953 \\
.02311 \\
.02703\end{array}$ & $\begin{array}{l}.00294 \\
.00325 \\
.00358 \\
.00392 \\
.00427\end{array}$ & $\begin{array}{l}.90 \\
.89 \\
.88 \\
.87 \\
.86\end{array}$ & $\begin{array}{l}.60 \\
.61 \\
.62 \\
.63 \\
.64\end{array}$ & $\begin{array}{r}.8328 \\
.8744 \\
.9179 \\
.9634 \\
1.0110\end{array}$ & $\begin{array}{l}.0416 \\
.0435 \\
.0455 \\
.0476 \\
.050\end{array}$ & $\begin{array}{l}.40 \\
.39 \\
.38 \\
.37 \\
.36\end{array}$ \\
\hline $\begin{array}{l}.15 \\
.16 \\
.17 \\
.18 \\
.19\end{array}$ & $\begin{array}{l}.03130 \\
.03592 \\
.04090 \\
.0426 \\
.05200\end{array}$ & $\begin{array}{l}.00462 \\
.00498 \\
.00536 \\
.00574 \\
.00613\end{array}$ & $\begin{array}{l}.85 \\
.84 \\
.83 \\
.82 \\
.81\end{array}$ & $\begin{array}{l}.65 \\
.66 \\
.67 \\
.68 \\
.69\end{array}$ & $\begin{array}{l}1.061 \\
1.113 \\
1.168 \\
1.225 \\
1.285\end{array}$ & $\begin{array}{l}.052 \\
.055 \\
.057 \\
.060 \\
.064\end{array}$ & $\begin{array}{l}.35 \\
.34 \\
.33 \\
.32 \\
.31\end{array}$ \\
\hline $\begin{array}{l}.20 \\
.21 \\
.22 \\
.23 \\
.24\end{array}$ & $\begin{array}{l}.05813 \\
.06647 \\
.07163 \\
.0702 \\
.08684\end{array}$ & $\begin{array}{l}.00654 \\
.00696 \\
.00739 \\
.00782 \\
.00828\end{array}$ & $\begin{array}{l}.80 \\
.79 \\
.78 \\
.77 \\
.76\end{array}$ & $\begin{array}{l}.70 \\
.71 \\
.72 \\
.73 \\
.74\end{array}$ & $\begin{array}{l}1.349 \\
1.415 \\
1.485 \\
1.559 \\
1.637\end{array}$ & $\begin{array}{l}.066 \\
.070 \\
.074 \\
.078 \\
.082\end{array}$ & $\begin{array}{l}.30 \\
.29 \\
.28 \\
.27 \\
.26\end{array}$ \\
\hline $\begin{array}{l}.25 \\
.26 \\
.27 \\
.28 \\
.29\end{array}$ & $\begin{array}{l}.09512 \\
.1039 \\
.1131 \\
.1228 \\
.1330\end{array}$ & $\begin{array}{l}.00878 \\
.0092 \\
.0097 \\
.0102 \\
.0108\end{array}$ & $\begin{array}{l}.75 \\
.74 \\
.73 \\
.72 \\
.71\end{array}$ & $\begin{array}{l}.75 \\
.76 \\
.77 \\
.78 \\
.79\end{array}$ & $\begin{array}{l}1.719 \\
1.806 \\
1.898 \\
1.995 \\
2.099\end{array}$ & $\begin{array}{l}.087 \\
.092 \\
.097 \\
.104 \\
.111\end{array}$ & $\begin{array}{l}.25 \\
.24 \\
.23 \\
.22 \\
.21\end{array}$ \\
\hline $\begin{array}{l}.30 \\
.31 \\
.32 \\
.33 \\
.34\end{array}$ & $\begin{array}{l}.1438 \\
.1551 \\
.1670 \\
.1794 \\
.1924\end{array}$ & $\begin{array}{l}.0113 \\
.0119 \\
.0124 \\
.0130 \\
.0137\end{array}$ & $\begin{array}{l}.70 \\
.69 \\
.68 \\
.67 \\
.66\end{array}$ & $\begin{array}{l}.80 \\
.81 \\
.82 \\
.83 \\
.84\end{array}$ & $\begin{array}{l}2.210 \\
2.328 \\
2.454 \\
2.590 \\
2.736\end{array}$ & $\begin{array}{l}.118 \\
.126 \\
.136 \\
.146 \\
.158\end{array}$ & $\begin{array}{l}.20 \\
.19 \\
.18 \\
.17 \\
.16\end{array}$ \\
\hline $\begin{array}{l}.35 \\
.36 \\
.37 \\
.38 \\
.39\end{array}$ & $\begin{array}{r}.2061 \\
.2203 \\
.2353 \\
.2509 \\
.2672\end{array}$ & $\begin{array}{l}.0142 \\
.0150 \\
.0156 \\
.0163 \\
.0171\end{array}$ & $\begin{array}{l}.65 \\
.64 \\
.63 \\
.62 \\
.61\end{array}$ & $\begin{array}{r}.85 \\
.88 \\
.87 \\
.88\end{array}$ & $\begin{array}{l}2.894 \\
3.065 \\
3.252 \\
3.457\end{array}$ & $\begin{array}{l}.171 \\
.187 \\
.205 \\
.227\end{array}$ & $\begin{array}{l}.15 \\
.14 \\
.13 \\
.12\end{array}$ \\
\hline $\begin{array}{l}.40 \\
.41 \\
.42 \\
.43 \\
.44\end{array}$ & $\begin{array}{l}.2843 \\
.3021 \\
.3207 \\
.3401 \\
.3604\end{array}$ & $\begin{array}{l}.0178 \\
.0186 \\
.0194 \\
.0203 \\
.0211\end{array}$ & $\begin{array}{l}.60 \\
.59 \\
.58 \\
.57 \\
.56\end{array}$ & $\begin{array}{l}.89 \\
.90 \\
.91 \\
.92 \\
.93\end{array}$ & $\begin{array}{l}3.684 \\
3.935 \\
4.218 \\
4.539 \\
4.908\end{array}$ & $\begin{array}{l}.251 \\
.283 \\
.321 \\
.369 \\
.433\end{array}$ & $\begin{array}{l}.11 \\
.10 \\
.09 \\
.08 \\
.07\end{array}$ \\
\hline $\begin{array}{l}.45 \\
.46 \\
.47 \\
.48 \\
.49 \\
.50\end{array}$ & $\begin{array}{r}.3815 \\
.4035 \\
.4265 \\
.4505 \\
.4755 \\
.5016\end{array}$ & $\begin{array}{l}.0220 \\
.0230 \\
.0240 \\
.0250 \\
.0261 \\
.0271\end{array}$ & $\begin{array}{l}.55 \\
.54 \\
.53 \\
.52 \\
.51 \\
.50\end{array}$ & $\begin{array}{r}.94 \\
.95 \\
.96 \\
.97 \\
.98 \\
.99 \\
1.00\end{array}$ & $\begin{array}{r}5.341 \\
5.861 \\
6.508 \\
7.356 \\
8.571 \\
10.685 \\
\infty\end{array}$ & $\begin{array}{r}.520 \\
.647 \\
.848 \\
1.215 \\
2.114 \\
\infty\end{array}$ & $\begin{array}{l}.06 \\
.05 \\
.04 \\
.03 \\
.02 \\
.01 \\
0 .\end{array}$ \\
\hline
\end{tabular}


TABLE 2.-Values of $H$ in the Equation $M=r_{1} H$ When the Circles are Close Together $\left(k^{2}>0.85\right)$

Method of Using TABLe TO Compute AN Inductance.-Compute $k^{2}$ and $r_{1}$ as in Table $\mathrm{I}$. Obtain $k^{\prime 2}$ from the relation $k^{\prime 2}=\mathrm{I}-k^{2}$, or compute from the equation

$$
k^{\prime 2}=\frac{(A-a)^{2}+D^{2}}{(A+a)^{2}+D^{2}}
$$

Find colog $k^{\prime 2}$. Use linear interpolation to get value of $H$ from table. Then $M=r_{1} H$.

Method of Using Table to Find Size and Positron of Circles Which Wril Give A Desired Inductance.-Method identical with that given under Table $\mathrm{I}$. Use this table only when necessary to interpolate between values given in Table $\mathrm{I}$.

UNIrs. $-A, a$, and $D$ in centimeters; $M$ in millimicrohenrys. If $A, a$, and $D$ are in inches, multiply the value of $H$ by 2.54 to give $M$ in millimicrohentys (thousandths of a microhenry).

ACCURACy.-Throughout the table, an accuracy of one-tenth of I per cent can be obtained by linear interpolation. For values of colog $k^{\prime 2}$ greater than 2.0 , an accuracy of one one-hundredth of I per cent can be obtained by linear interpolation.

\begin{tabular}{|c|c|c|c|c|c|c|c|c|c|}
\hline$\underset{k^{\prime 2}}{\text { Colog }}$ & $H$ & $\begin{array}{c}\text { Differ- } \\
\text { ence }\end{array}$ & $k^{\prime 2}$ & $k^{2}$ & $\underset{k^{\prime 2}}{\text { Colog }}$ & $H$ & $\begin{array}{l}\text { Differ- } \\
\text { ence }\end{array}$ & $k^{\prime 2}$ & $k^{2}$ \\
\hline $\begin{array}{l}0.8 \\
.9 \\
1.0 \\
1.1 \\
1.2\end{array}$ & $\begin{array}{l}2.759 \\
\text { 3. } 334 \\
3.935 \\
4.558 \\
5.199\end{array}$ & $\begin{array}{l}675 \\
601 \\
623 \\
641 \\
655\end{array}$ & $\begin{array}{c}0.1585 \\
.1259 \\
.1000 \\
.07943 \\
.06310\end{array}$ & $\begin{array}{r}0.8415 \\
.8741 \\
.9000 \\
.9206 \\
.9369\end{array}$ & $\begin{array}{l}2.5 \\
2.6 \\
2.7\end{array}$ & $\begin{array}{l}14.255 \\
14.973 \\
15.692 \\
16.413\end{array}$ & $\begin{array}{l}718 \\
710 \\
720 \\
721\end{array}$ & $\begin{array}{r}0.003162 \\
.002512 \\
.001995 \\
.001585\end{array}$ & $\begin{array}{r}0.9968 \\
.9975 \\
.9980 \\
.9984\end{array}$ \\
\hline $\begin{array}{l}1.3 \\
1.4 \\
1.5 \\
1.6 \\
1.7\end{array}$ & $\begin{array}{l}5.854 \\
6.522 \\
7.198 \\
7.885 \\
8.578\end{array}$ & $\begin{array}{l}668 \\
676 \\
687 \\
693 \\
698\end{array}$ & $\begin{array}{l}.05012 \\
.03981 \\
.03162 \\
.02512 \\
01995\end{array}$ & $\begin{array}{l}.9799 \\
.9602 \\
.9684 \\
.9749 \\
9801\end{array}$ & $\begin{array}{l}3.9 \\
3.1 \\
3.2 \\
3.3\end{array}$ & $\begin{array}{l}17.135 \\
17.85 \\
18.576 \\
19.298\end{array}$ & $\begin{array}{l}720 \\
722 \\
721 \\
722 \\
772\end{array}$ & $\begin{array}{l}.001000 \\
.0007943 \\
.0006310\end{array}$ & $\begin{array}{r}.9987 \\
.9990 \\
.9992 \\
.9994\end{array}$ \\
\hline 1.7 & 9. 276 & 703 & $\begin{array}{l}.01995 \\
.01585\end{array}$ & .9801 & $\begin{array}{l}3.3 \\
3.4 \\
3.5\end{array}$ & $\begin{array}{l}0.020 \\
20.742 \\
21.465\end{array}$ & $\begin{array}{l}722 \\
723 \\
723 \\
723\end{array}$ & $\begin{array}{r}.0005012 \\
.0003911 \\
.0003162 \\
0.0025251\end{array}$ & $\begin{array}{r}.99959 \\
.99967 \\
.9997\end{array}$ \\
\hline $\begin{array}{l}1.9 \\
2.0\end{array}$ & $\begin{array}{r}9.979 \\
10.685\end{array}$ & $\begin{array}{l}706 \\
710\end{array}$ & $\begin{array}{l}.01259 \\
.01000\end{array}$ & $\begin{array}{r}9874 \\
.9900\end{array}$ & 3. 6 & 22. 1 & 723 & .0002512 & 9997 \\
\hline $\begin{array}{l}2.1 \\
2.2\end{array}$ & $\begin{array}{l}11.395 \\
12.107\end{array}$ & $\begin{array}{l}712 \\
714\end{array}$ & .006310 & . 9937 & $\begin{array}{l}3.7 \\
3.8\end{array}$ & $\begin{array}{l}23.911 \\
23.634\end{array}$ & $\begin{array}{l}723 \\
723 \\
773\end{array}$ & .0001585 & . \\
\hline $\begin{array}{l}\text { 2. } 3 \\
2.4\end{array}$ & $\begin{array}{l}\text { 12. } 821 \\
13.537\end{array}$ & $\begin{array}{l}716 \\
718\end{array}$ & $\begin{array}{c}.005012 \\
.003981\end{array}$ & $\begin{array}{r}9950 \\
.9960\end{array}$ & 4. 0 & 25.080 & & .0001000 & . \\
\hline
\end{tabular}


TABLE 3.-Values of $H$ in the Equation $M=r_{1} H$ When the Circles Are Far Apart $\left(k^{2}<0.1\right)$

Method of Using TABLe to Compute AN Inductance.-Compute $k^{2}$ and $r_{1}$ as in Table r. Obtain $k^{4}$. Use linear interpolation to get value of $H$. Then $M=r_{1} H$.

Method of Using Table to Obtain Size and Position of Circles Which Give a Desired Inductance.-Method identical with that given under Table I. Use this table only when necessary to interpolate between values given in Table $\mathrm{I}$.

UNITS. $-A, a$, and $D$ in centimeters; in millimicrohenrys. If $A, a$, and $D$ are in inches, multiply the value of $H$ by 2.54 to give $M$ in millimicrohenrys (thousandths of a microhenry).

ACCURACY.-Throughout the range of this table, $H$ is nearly a linear function of $k^{4}$. However, as both $k^{4}$ and $H$ start at zero, the percentage error in $H$ may be large when $k^{4}$ is very small. Hence when $k^{4}$ is less than -0.00I, it is better to compute the mutual iuductance by the formula

$$
M=\mathrm{I} .2337 r_{1} k^{4}\left(\mathrm{I}+3 / 4 k^{2}\right)
$$

This formula will give an accuracy greater than one-tenth of $\mathrm{I}$ per cent when $k^{4}$ is less than $0.00 \mathrm{r}$. When $k^{4}$ is greater than $0.00 \mathrm{r}$ and less than 0.010 , an accuracy greater than one-tenth of I per cent can be obtained by the use of the table.

\begin{tabular}{|c|c|c|c|c|c|c|c|c|c|}
\hline$k^{4}$ & $H$ & $\begin{array}{c}\text { Differ- } \\
\text { ence }\end{array}$ & $k^{2}$ & $\ell^{\prime 2}$ & $k^{4}$ & $H$ & $\begin{array}{c}\text { Differ- } \\
\text { ence }\end{array}$ & $k^{2}$ & $k^{\prime 2}$ \\
\hline $\begin{array}{l}0 \\
.001 \\
.002 \\
.003 \\
.004 \\
.005\end{array}$ & $\begin{array}{l}0 \\
.001264 \\
.002553 \\
.003860 \\
.005181 \\
.006515\end{array}$ & $\begin{array}{l}1,264 \\
1,289 \\
1,307 \\
1,321 \\
1,334 \\
1,345\end{array}$ & $\begin{array}{l}0 \\
.03162 \\
.04472 \\
.05477 \\
.06325 \\
.07071\end{array}$ & $\begin{array}{c}1.000 \\
.9684 \\
.9553 \\
.9452 \\
.3568 \\
.9297\end{array}$ & $\begin{array}{l}0.006 \\
.007 \\
.008 \\
.009 \\
.010\end{array}$ & $\begin{array}{r}0.007860 \\
.009216 \\
.010582 \\
.011957 \\
.013341\end{array}$ & $\begin{array}{l}1,356 \\
1,366 \\
1,375 \\
1,384\end{array}$ & $\begin{array}{r}0.07746 \\
.08367 \\
.08944 \\
.09467 \\
.10000\end{array}$ & $\begin{array}{r}0.9225 \\
.9163 \\
.9106 \\
.9053 \\
.9000\end{array}$ \\
\hline
\end{tabular}




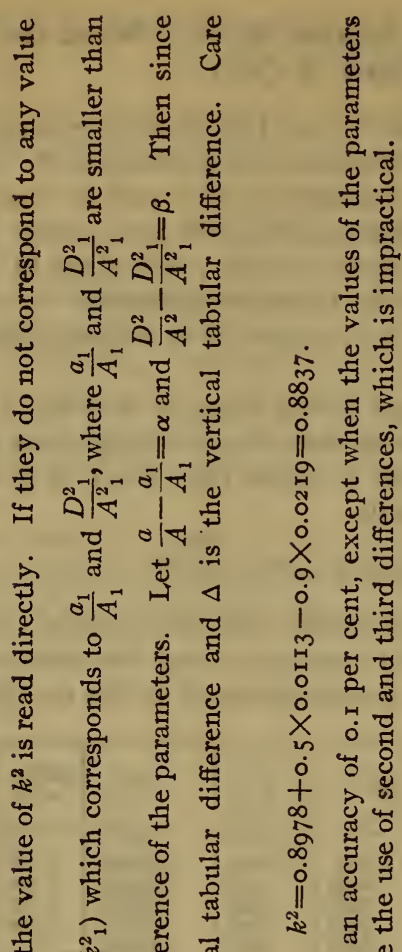

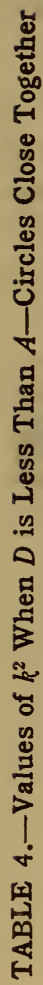




\begin{tabular}{|c|c|c|c|c|c|}
\hline 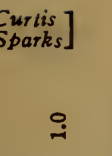 & 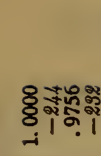 & 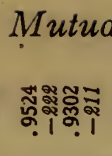 & 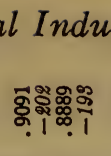 & 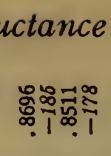 & of $\mathrm{Coa}$ \\
\hline . & $8: 8$ & $8: 1$ & $9: 8$ & $9 \%$ & 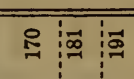 \\
\hline : & 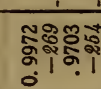 & 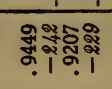 & 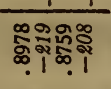 & 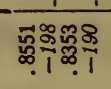 & 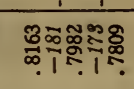 \\
\hline$\circ$ & 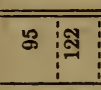 & 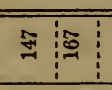 & 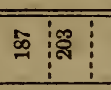 & 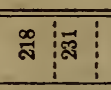 & ; \\
\hline$\stackrel{8}{\circ}$ & 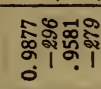 & 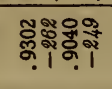 & 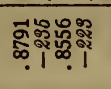 & 象: & 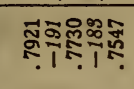 \\
\hline$\circ$ & 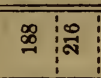 & $7 \%$ & 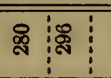 & 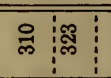 & 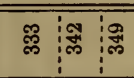 \\
\hline 8 & 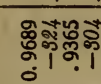 & 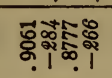 & 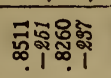 & 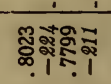 & 象路 \\
\hline$\infty$ & 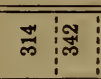 & 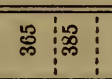 & $8: 17$ & $\begin{array}{ll}819 \\
8\end{array}$ & 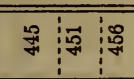 \\
\hline$\because$ & 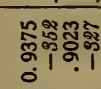 & 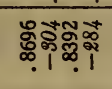 & 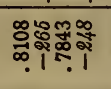 & 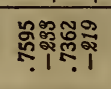 & 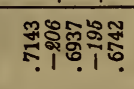 \\
\hline$\circ$ & $8: 9$ & 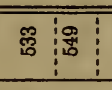 & $\begin{array}{c:c:}5: 5: \\
\end{array}$ & 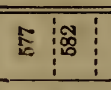 & 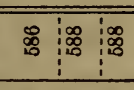 \\
\hline n' & 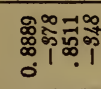 & 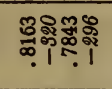 & 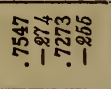 & 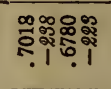 & 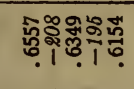 \\
\hline$\circ$ & $8 \%$ & $8 \%$ & $8: 8$ & 8 & $8: 9$ \\
\hline : & 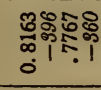 & ริำ & 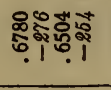 & 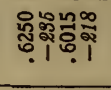 & 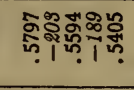 \\
\hline . & 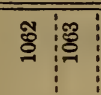 & 梁: & 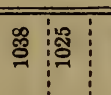 & 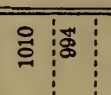 & 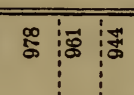 \\
\hline \% & 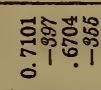 & 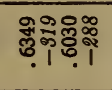 & 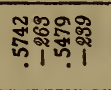 & 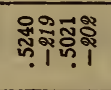 & 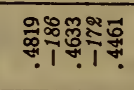 \\
\hline . & 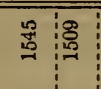 & 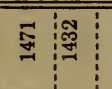 & 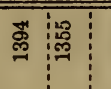 & 贯 & 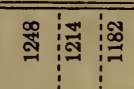 \\
\hline g & 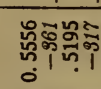 & 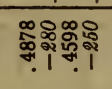 & 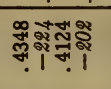 & 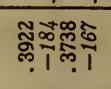 & 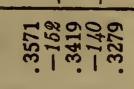 \\
\hline . & 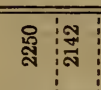 & 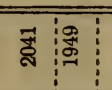 & 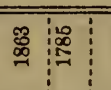 & E: : & 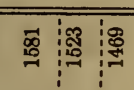 \\
\hline 5 & 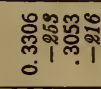 & 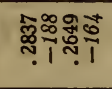 & 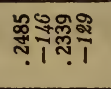 & 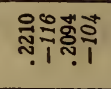 & 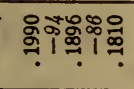 \\
\hline . & 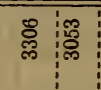 & 管: & 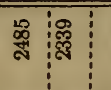 & \&: & 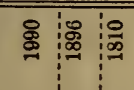 \\
\hline$\circ$ & 0 & 0 & 0 & 0 & $0: 0$ \\
\hline$\stackrel{100 / \pi}{\rightarrow / 8}$ & & & & & ; \\
\hline
\end{tabular}




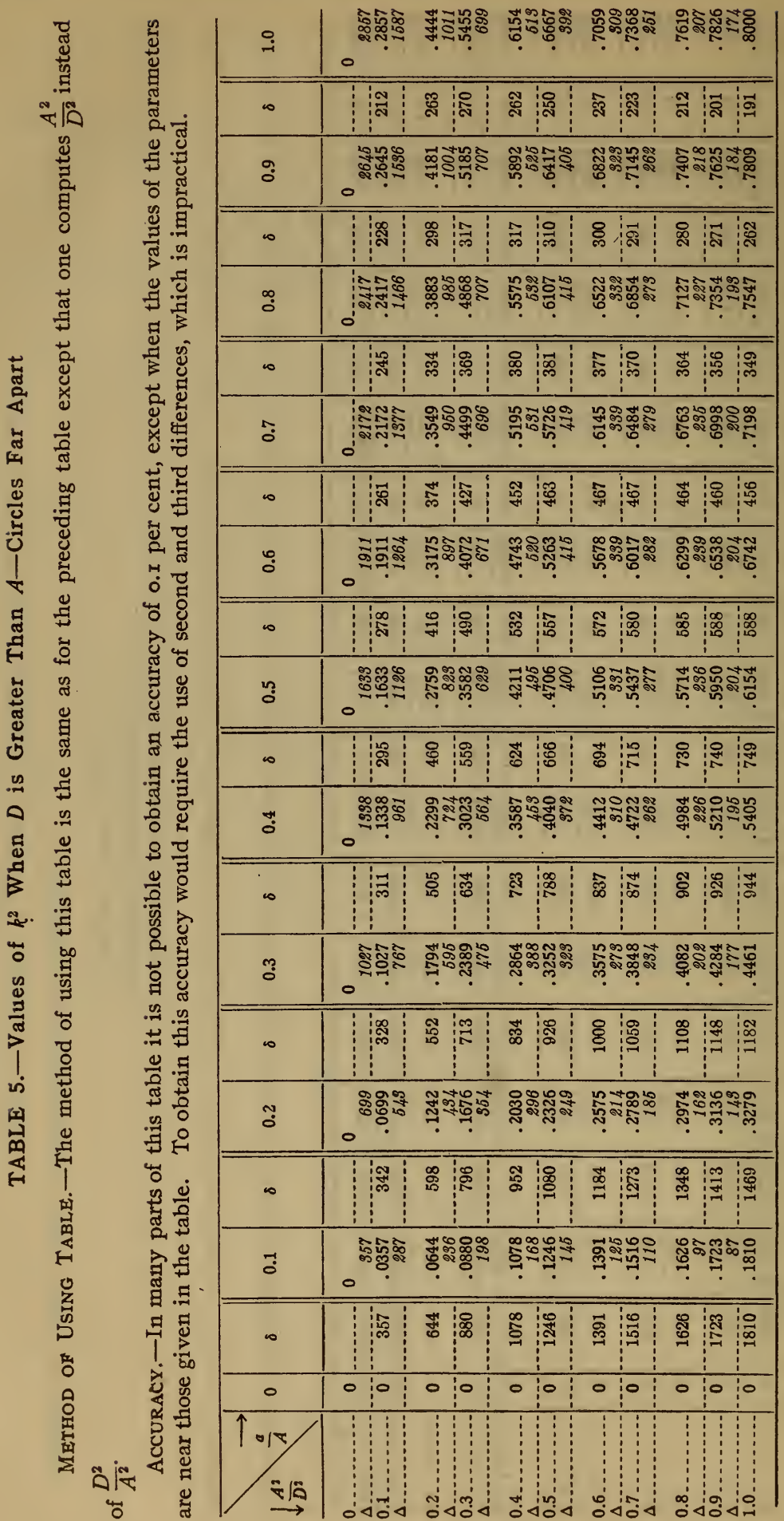




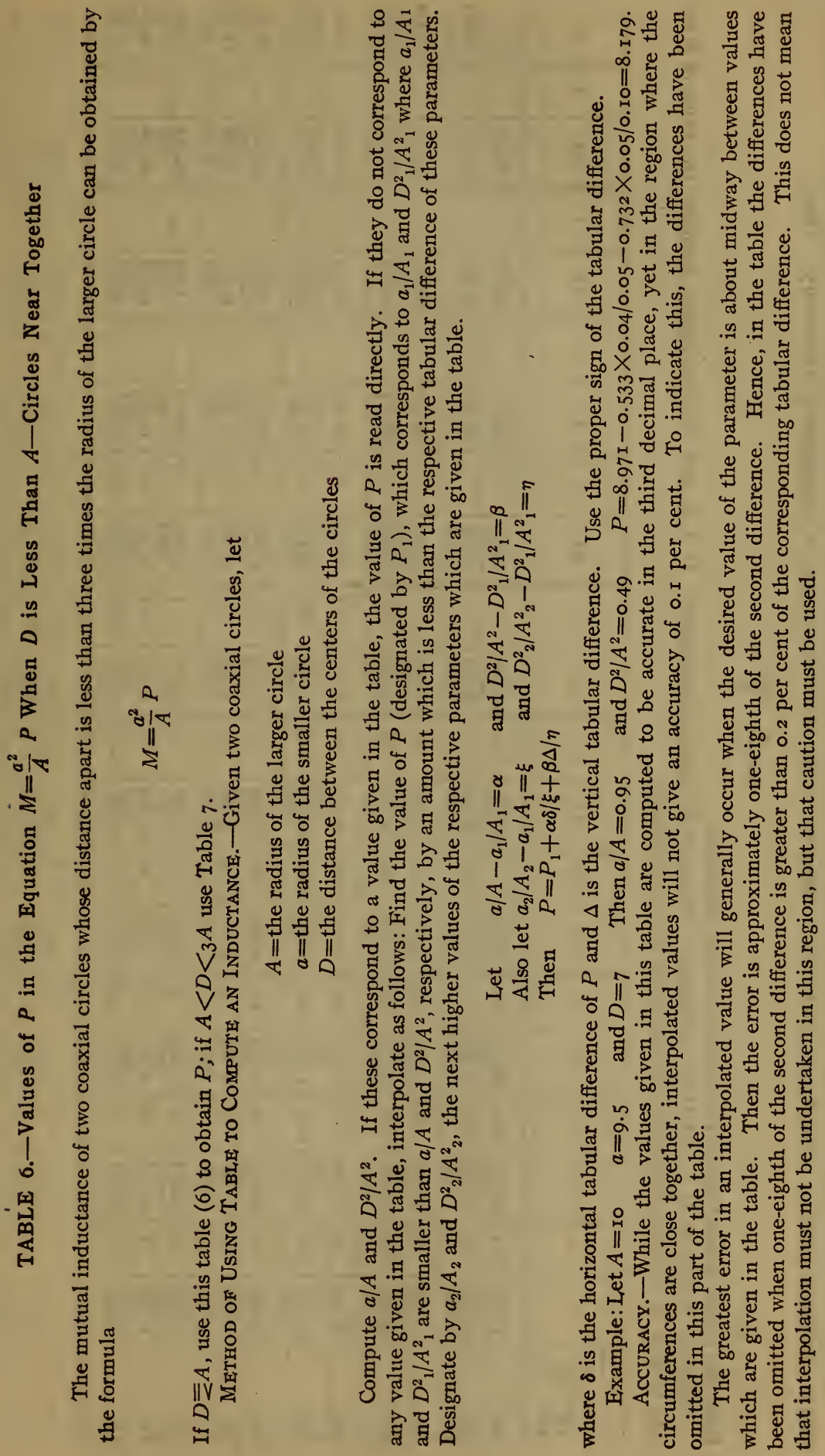




\begin{tabular}{|c|c|c|c|c|c|c|}
\hline$\stackrel{-}{-1}$ & & 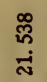 & $\begin{array}{l}\text { : } \\
9\end{array}$ & 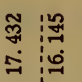 & 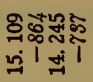 & 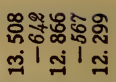 \\
\hline$\infty$ & & & & & & \\
\hline ò & 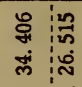 & $\begin{array}{l}\hat{\jmath} \\
\text { స่ }\end{array}$ & $\begin{array}{l}\text { o } \\
\text { : } \\
\text { ᄋ }\end{array}$ & 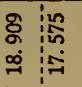 & 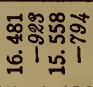 & 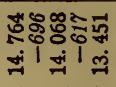 \\
\hline$\infty$ & & & & & & \\
\hline$\stackrel{\substack{0 \\
0}}{ }$ & 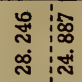 & 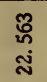 & 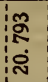 & 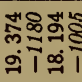 & 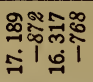 & 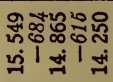 \\
\hline
\end{tabular}

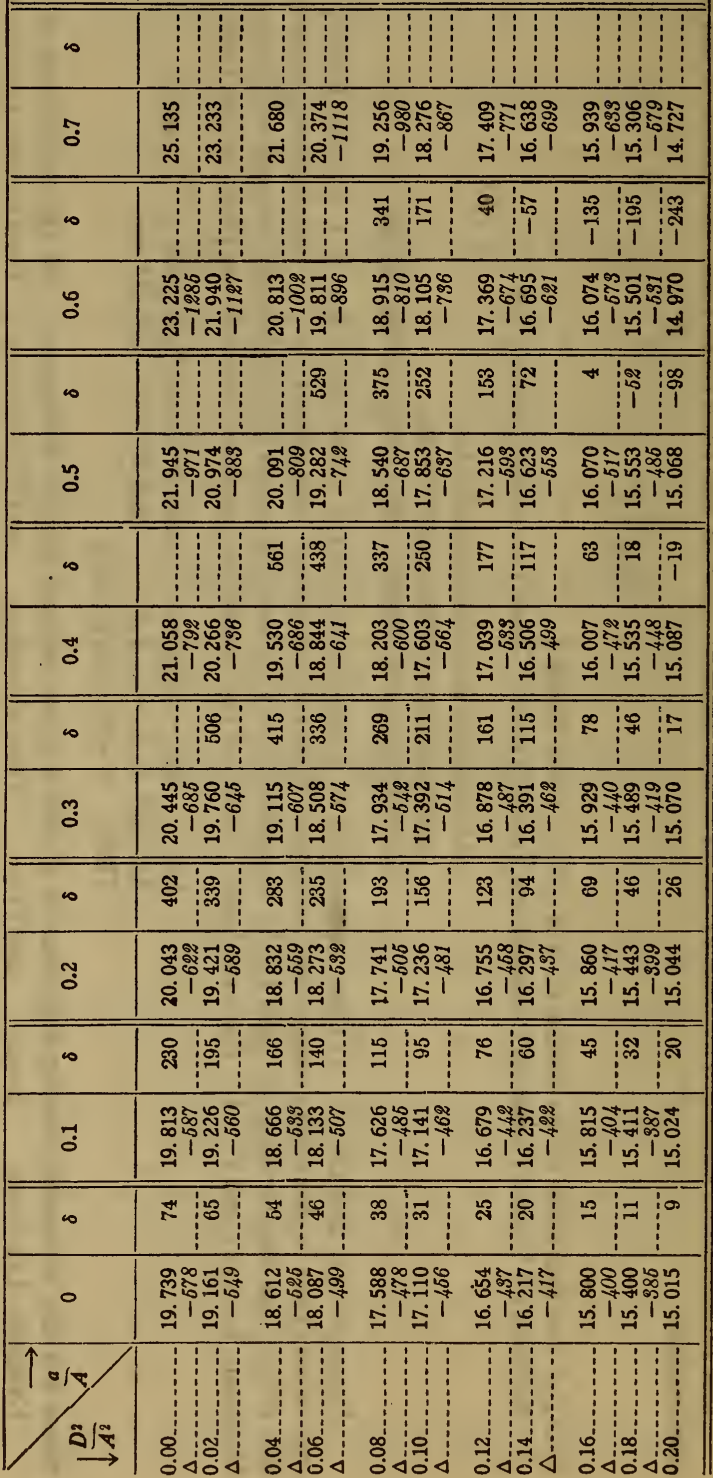




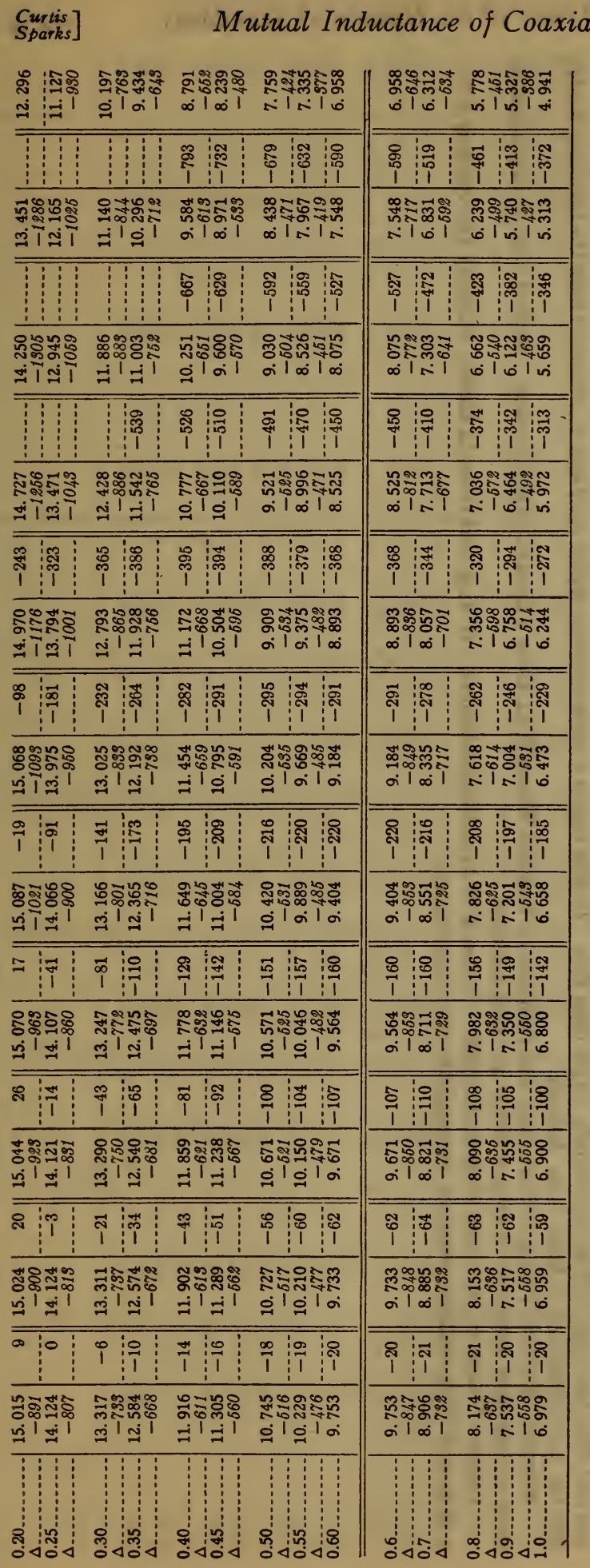




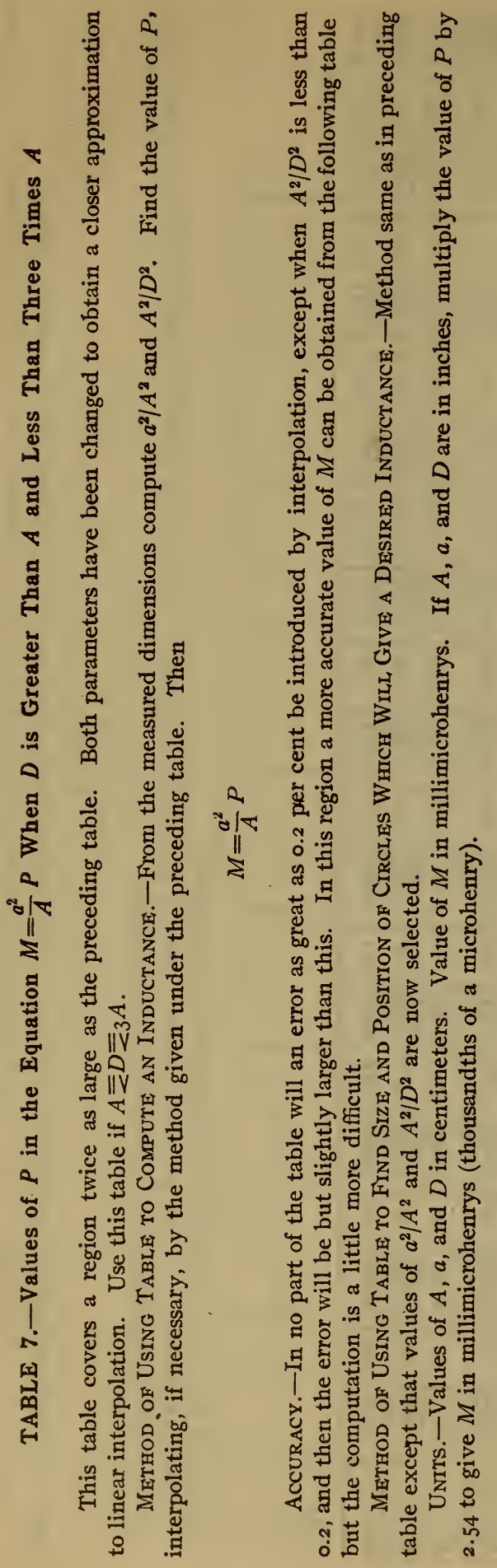




\begin{tabular}{|c|c|c|c|c|c|c|}
\hline & \multicolumn{6}{|c|}{ Mutual Inductance of Coaxial Circles } \\
\hline$\stackrel{-}{-}$ & 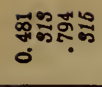 & 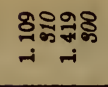 & 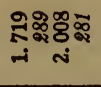 & 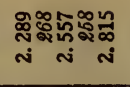 & 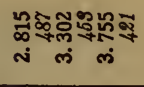 & 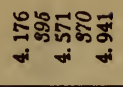 \\
\hline$\infty$ & \begin{tabular}{l:l:l}
\multirow{2}{*}{1} & 1 \\
\end{tabular} & $\begin{array}{l:l:l}\overrightarrow{4} & 0 \\
& 1 \\
\end{array}$ & $\begin{array}{l:l:l}7 & 18 \\
1 & 1\end{array}$ & $\begin{array}{l:l:l}0 & 0 \\
1 & 1 & 1 \\
\end{array}$ & $\begin{array}{l:l:l}0 & 0 & 0 \\
1 & 1 & 1\end{array}$ & 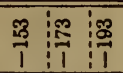 \\
\hline à & 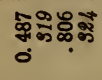 & 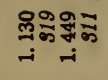 & 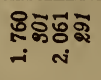 & 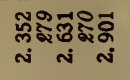 & 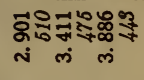 & 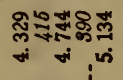 \\
\hline$\infty$ & $\begin{array}{l:l:l}1 & 1 \\
& 1 & \\
\end{array}$ & $\begin{array}{l:l}\vec{i} \\
i\end{array}$ & \begin{tabular}{l:l}
\multirow{1}{*}{$\mathrm{i}$} & $\mathrm{i}$ \\
\end{tabular} & $\left.\begin{array}{l:l:l}0 \\
10\end{array}\right)$ & $\begin{array}{l:l:l}\infty & 0 \\
1 & 0 & 1 \\
\end{array}$ & $\begin{array}{l:l:l}5 & 8 \\
1 & 1 & 1 \\
1\end{array}$ \\
\hline$\stackrel{\infty}{0}$ & 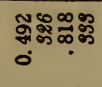 & చ్రాఖ్ & 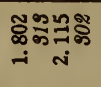 & 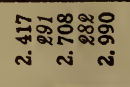 & 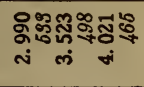 & 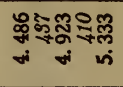 \\
\hline • & $\begin{array}{l:l:}0 & \\
& 1\end{array}$ & 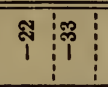 & \begin{tabular}{l:l|l}
7 & 0 \\
1 & 1 & \\
\end{tabular} & 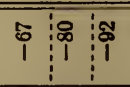 & 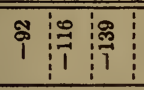 & 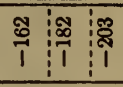 \\
\hline s̊ & 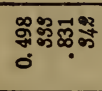 & 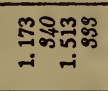 & 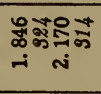 & 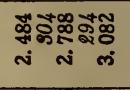 & 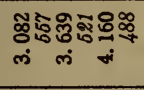 & 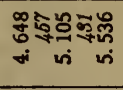 \\
\hline$\infty$ & $\begin{array}{l:l:}i & 9 \\
\end{array}$ & 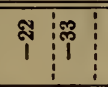 & 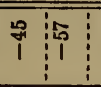 & 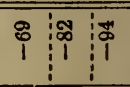 & 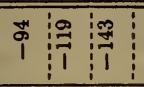 & \begin{tabular}{c:c:c}
\multirow{0}{*}{} & 0 \\
1 & 0 & 0 \\
1 & 1 \\
\end{tabular} \\
\hline$\stackrel{\circ}{\circ}$ & 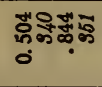 & 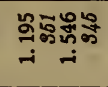 & 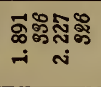 & 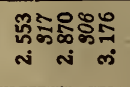 & 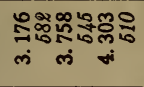 & 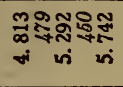 \\
\hline$\infty$ & $\begin{array}{l:l:}i & 1 \\
\end{array}$ & 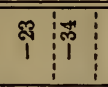 & $\begin{array}{l:l:}j & 0 \\
& 1 \\
\end{array}$ & 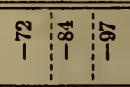 & 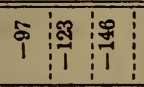 & 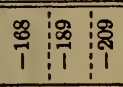 \\
\hline aे & 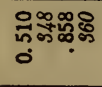 & 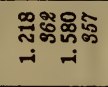 & 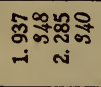 & 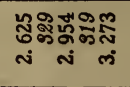 & 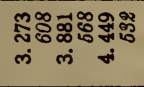 & 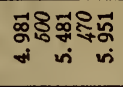 \\
\hline$\infty$ & $\begin{array}{l:l:}i & 1 \\
\end{array}$ & \begin{tabular}{l:ll}
\multirow{1}{*}{} & 0 \\
\end{tabular} & $\begin{array}{l:l:}i & 0 \\
\end{array}$ & \begin{tabular}{l:l:l}
\multirow{1}{*}{} & 0 & 0 \\
1 & 1 & 1 \\
\end{tabular} & $\begin{array}{l:l:l}0 & 0 & 9 \\
& 1 & 1 \\
\end{array}$ & 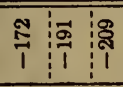 \\
\hline$\ddot{0}$ & 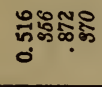 & 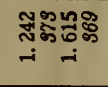 & 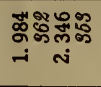 & 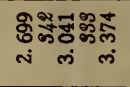 & 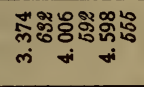 & 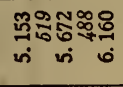 \\
\hline$\infty$ & $\begin{array}{l:l:l}i & \\
1 & 1 & \end{array}$ & 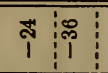 & $\begin{array}{l:l:l}g & 0 \\
& 0 & 1 \\
\end{array}$ & ב: & 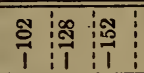 & 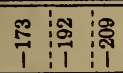 \\
\hline \% & 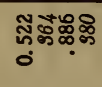 & 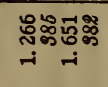 & 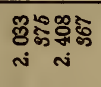 & 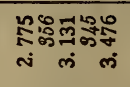 & 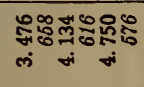 & 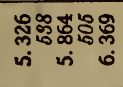 \\
\hline$\infty$ & $\begin{array}{l:l:l}1 & 1 \\
\end{array}$ & 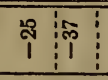 & \begin{tabular}{l|l:l}
0 & 0 \\
1 & 1 & \\
\end{tabular} & $\begin{array}{l:l:l}\infty & 0 \\
& 10 & 1 \\
\end{array}$ & 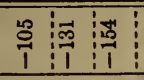 & 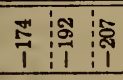 \\
\hline 요 & 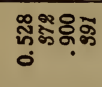 & సేస్టి & 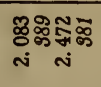 & 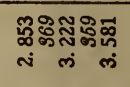 & 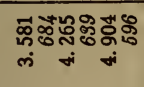 & 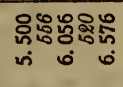 \\
\hline$\infty$ & $\begin{array}{l:l:l}i & \\
& 1 & \end{array}$ & 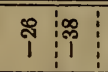 & \begin{tabular}{l:l:l}
\multirow{2}{*}{0} & 0 \\
& 1 & \\
\end{tabular} & $\begin{array}{l:l:l}0 & 0 \\
& 1 & 0 \\
1\end{array}$ & $\begin{array}{l:l:l}0 & 0 \\
& 0 & 0\end{array}$ & 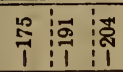 \\
\hline $\overrightarrow{0}$ & 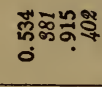 & 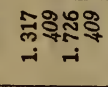 & 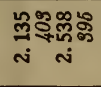 & 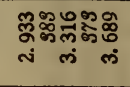 & 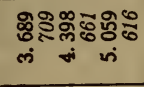 & 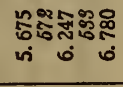 \\
\hline$\infty$ & $\begin{array}{l:l:l} & 1 & 0 \\
\end{array}$ & $\begin{array}{l:l:l}0 & \\
1 & 1 \\
\end{array}$ & $\begin{array}{l:l:l}0 & 0 \\
1 & 1 & 1 \\
1 & 1 & \\
\end{array}$ & $\begin{array}{l:l:}\mathbf{p} & 8 \\
1 & 1 \\
\end{array}$ & 只: & 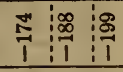 \\
\hline 0 & 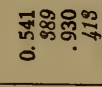 & 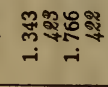 & 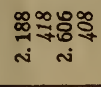 & 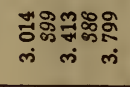 & 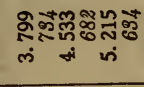 & 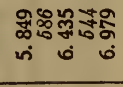 \\
\hline 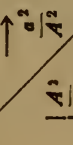 & & $\begin{array}{l}1 \\
\text { a d n } \\
0<0\end{array}$ & 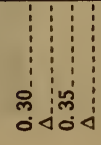 & 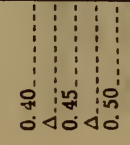 & 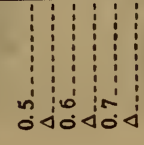 & 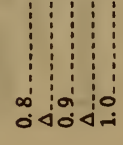 \\
\hline
\end{tabular}




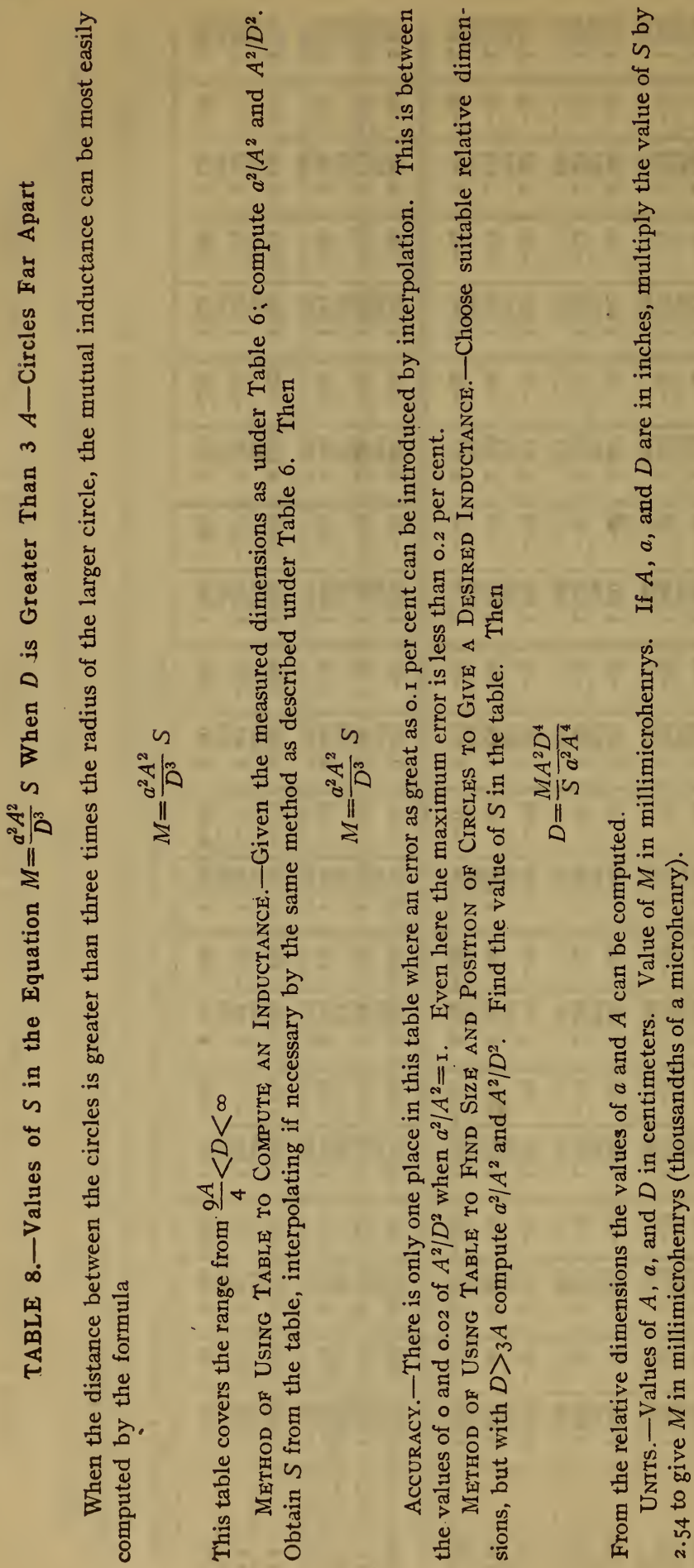




\begin{tabular}{|c|c|c|c|c|c|}
\hline$\stackrel{9}{9}$ & 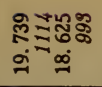 & 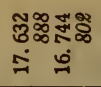 & 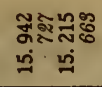 & 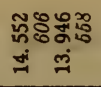 & 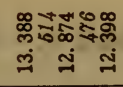 \\
\hline$\infty$ & $\begin{array}{l:l}0 \\
\end{array}$ & $\bar{\sigma}$ & 苟: & $\begin{array}{c:c}\mathbf{a} \\
\mathbf{9}\end{array}$ & సి:สి \\
\hline oे & 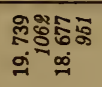 & 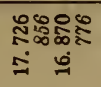 & 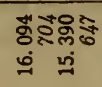 & 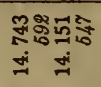 & 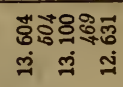 \\
\hline • & 0 & 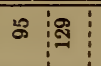 & 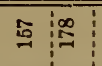 & $\bar{a}$ & 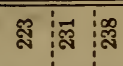 \\
\hline$\stackrel{\infty}{0}$ & 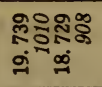 & 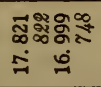 & 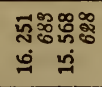 & 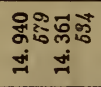 & 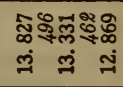 \\
\hline$\infty$ & $\begin{array}{l:l}0 \\
\end{array}$ & $\begin{array}{l:l}\circ \\
0\end{array}$ & $\stackrel{\circ}{\circ}$ & \begin{tabular}{l:l}
8 \\
\multirow{2}{*}{}
\end{tabular} & 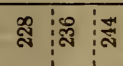 \\
\hline ó & 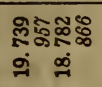 & 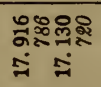 & 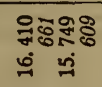 & 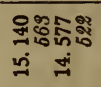 & 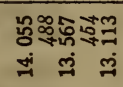 \\
\hline$\infty$ & $\begin{array}{l:l}0 \\
0\end{array}$ & 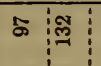 & 8 & 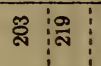 & 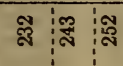 \\
\hline$\stackrel{\circ}{\circ}$ & 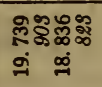 & 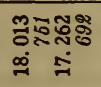 & 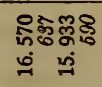 & 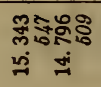 & 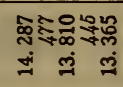 \\
\hline$\infty$ & $\begin{array}{l:ll}0 \\
0.0\end{array}$ & $\begin{array}{l:l}\infty \\
\infty\end{array}$ & $\Phi: \infty$ & : : & 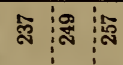 \\
\hline na & 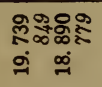 & 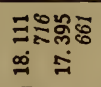 & 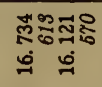 & 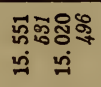 & 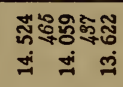 \\
\hline$\infty$ & $\begin{array}{l:l}0 \\
0\end{array}$ & $\begin{array}{l:l}\ddot{9} \\
口\end{array}$ & $8: 8$ & \begin{tabular}{l:l}
\multirow{2}{*}{ ส } \\
क
\end{tabular} & 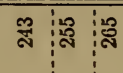 \\
\hline$\ddot{0}$ & 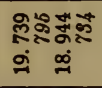 & 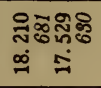 & 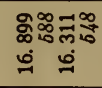 & 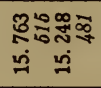 & 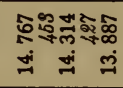 \\
\hline$\infty$ & $\begin{array}{l:ll}0 \\
0\end{array}$ & $8:$ & $\stackrel{\infty}{\stackrel{9}{-}}$ & : : & 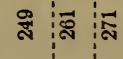 \\
\hline$\stackrel{m}{0}$ & 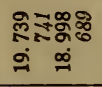 & 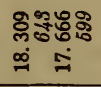 & 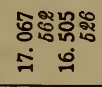 & 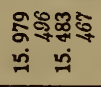 & 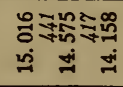 \\
\hline$\infty$ & $\circ$ & 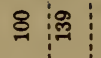 & 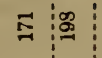 & वี & 蚂: \\
\hline กี & 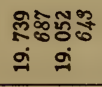 & 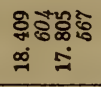 & 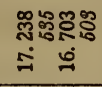 & 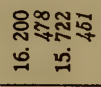 & 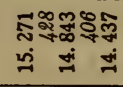 \\
\hline$\infty$ & $\begin{array}{l:l}0 \\
0\end{array}$ & $\bar{D}: \exists$ & ס: & ฮี : & 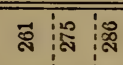 \\
\hline İ & 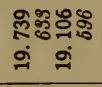 & 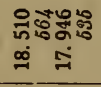 & 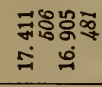 & 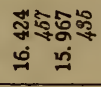 & 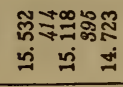 \\
\hline 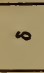 & $\begin{array}{l:l}0 \\
\end{array}$ & 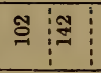 & 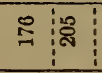 & $\begin{array}{c:c}\text { ลิ } \\
\end{array}$ & 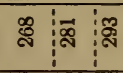 \\
\hline$\circ$ & 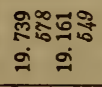 & 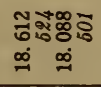 & 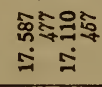 & 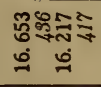 & 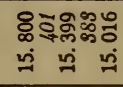 \\
\hline & & 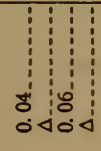 & $\begin{array}{l}\infty \\
0 \\
0\end{array}$ & $\begin{array}{ll}3 \\
0404\end{array}$ & $\begin{array}{l}0 \\
040 \\
0<0<0\end{array}$ \\
\hline
\end{tabular}


TABLE 9.-Values of $\frac{(\mid 2 n)^{2}}{2^{4 n}(\mid \underline{n})^{4}}$

The above expression appears in all the formulas for mutual inductance given in this paper. By the use of this table, the series can be easily extended to the twentysixth term. Let

$$
\frac{(\underline{2 n})^{2}}{2^{4 n}(\underline{n})^{4}}=\psi
$$

\begin{tabular}{|c|c|c|c|c|c|}
\hline$n$ & $\log \psi+10$ & $\psi$ & $n$ & $\log \psi+10$ & $\psi$ \\
\hline $\begin{array}{l}0 . \\
11- \\
2- \\
3 \\
4 \\
5-\end{array}$ & $\begin{array}{r}10.000000 \\
9.397940 \\
9.148062 \\
8.989700 \\
8.873718 \\
8.782202\end{array}$ & $\begin{array}{r}1.0000000 \\
0.2500000 \\
.1406250 \\
.0976563 \\
.0747684 \\
.0605623\end{array}$ & $\begin{array}{l}13-. . \\
14-. \\
15-. \\
16-. \\
17-. \\
18-.\end{array}$ & $\begin{array}{l}8.380558 \\
8.348970 \\
8.319520 \\
8.291944 \\
8.266014 \\
8.241546\end{array}$ & $\begin{array}{r}0.0240192 \\
.0223342 \\
.0208699 \\
.019559 \\
.0184507 \\
.0174400\end{array}$ \\
\hline $\begin{array}{r}6 \\
7-\ldots \\
8 \\
9-\cdots \\
10 . . .\end{array}$ & $\begin{array}{l}8.706626 \\
8.642252 \\
8.586196 \\
8.536550 \\
8.491998\end{array}$ & $\begin{array}{l}.0508892 \\
.0438785 \\
.0385652 \\
.0343993 \\
.0310455\end{array}$ & 19. & $\begin{array}{l}\text { 8. } 218380 \\
8.196390 \\
8.175460 \\
8.155940 \\
8.136404\end{array}$ & $\begin{array}{l}.0165341 \\
.0157177 \\
.0149782 \\
.0143051 \\
.0136900\end{array}$ \\
\hline & $\begin{array}{l}8.451590 \\
8.414624\end{array}$ & $\begin{array}{l}.0282872 \\
.0259791\end{array}$ & $24 \ldots$ & $\begin{array}{l}8.118114 \\
8.100566\end{array}$ & $\begin{array}{l}.0131254 \\
.0126057\end{array}$ \\
\hline
\end{tabular}

